\title{
Cation- and pH-Dependent Hydrogen Evolution and Oxidation Reaction Kinetics
}

\author{
Botao Huang,* Reshma R. Rao, Sifan You, Kyaw Hpone Myint, Yizhi Song, Yanming Wang, \\ Wendu Ding, Livia Giordano, Yirui Zhang, Tao Wang, Sokseiha Muy, Yu Katayama, Jeffrey C. Grossman, \\ Adam P. Willard, Kang Xu, Ying Jiang, and Yang Shao-Horn*
}

Cite This: JACS Au 2021, 1, 1674-1687

Read Online

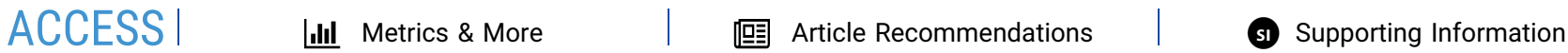

ABSTRACT: The production of molecular hydrogen by catalyzing water splitting is central to achieving the decarbonization of sustainable fuels and chemical transformations. In this work, a series of structure-making/breaking cations in the electrolyte were investigated as spectator cations in hydrogen evolution and oxidation reactions (HER/HOR) in the $\mathrm{pH}$ range of 1 to 14 , whose kinetics was found to be altered by up to 2 orders of magnitude by these cations. The exchange current density of HER/HOR was shown to increase with greater structure-making tendency of cations in the order of $\mathrm{Cs}^{+}<\mathrm{Rb}^{+}<\mathrm{K}^{+}<\mathrm{Na}^{+}<\mathrm{Li}^{+}$, which was accompanied by decreasing reorganization energy from the Marcus-Hush-Chidsey formalism and increasing reaction

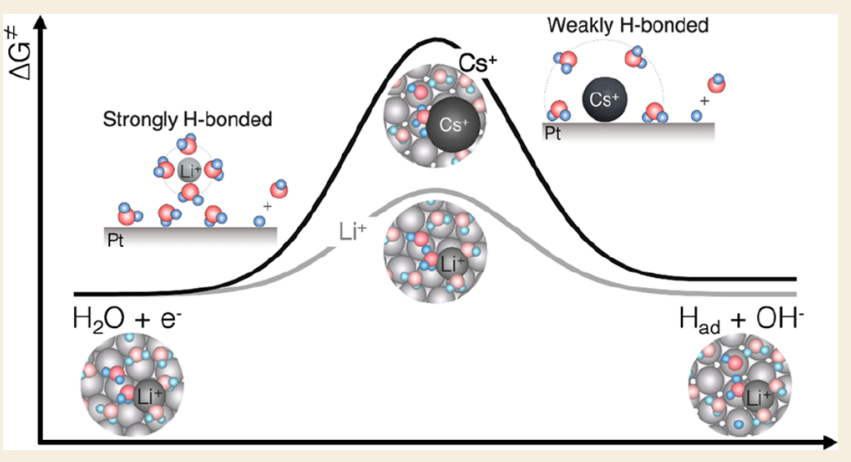
entropy. Invoking the Born model of reorganization energy and reaction entropy, the static dielectric constant of the electrolyte at the electrified interface was found to be significantly lower than that of bulk, decreasing with the structure-making tendency of cations at the negatively charged Pt surface. The physical origin of cation-dependent HER/HOR kinetics can be rationalized by an increase in concentration of cations on the negatively charged $\mathrm{Pt}$ surface, altering the interfacial water structure and the H-bonding network, which is supported by classical molecular dynamics simulation and surface-enhanced infrared absorption spectroscopy. This work highlights immense opportunities to control the reaction rates by tuning interfacial structures of cation and solvents.

KEYWORDS: hydrogen evolution/oxidation reaction, reorganization energy, reaction entropy, interfacial static dielectric constant, interfacial water, Marcus-Hush-Chidsey formalism, structure-making/breaking ion, Born model

\section{INTRODUCTION}

Catalyzing water splitting, specifically water reduction to produce molecular hydrogen, is central to achieving high efficiency of chemical transformations for carbon-free or carbon-neutral energy carriers. Significant efforts have been focused on design principles or activity descriptors of catalysts by tuning the covalent adsorbate-surface interaction using surface electronic structure features, ${ }^{1,2}$ which have greatly aided mechanistic understanding of the reactions and discovery of new catalysts with enhanced activity. ${ }^{1,3}$ For example, tuning the d-band center relative to the Fermi level ${ }^{4,5}$ of metals can control the binding energy of surface adsorbates such as adsorbed hydrogen $\left(\mathrm{H}_{\mathrm{ad}}\right)$ or hydroxyl $\left(\mathrm{OH}_{\mathrm{ad}}\right)$ and consequently dictate the catalytic activity of reactions such as the hydrogen oxidation/evolution reaction (HER/HOR). ${ }^{6-10}$ Recently, there are many examples of catalysts that show cation-dependent $^{11}$ and $\mathrm{pH}$-dependent ${ }^{9,12}$ catalytic activity, which can result from noncovalent interactions associated with water molecules, spectator ions, surface adsorbates, and electrified interfaces. ${ }^{13}$ For example, the exchange current density of HER/HOR normalized to the electrochemical surface area (ECSA) on platinum group metals in acid ${ }^{14,15}$ is about 2 orders of magnitude higher than that in base, ${ }^{16}$ where the activity decreases linearly with increasing $\mathrm{pH}^{8,9}$ Moreover, the catalytic activity of $\mathrm{HOR}$, oxygen reduction reaction (ORR), and methanol oxidation on platinum measured at 0.9 $\mathrm{V}$ versus the reversible hydrogen electrode (RHE) is cationdependent, increasing with spectator cations in the order of $\mathrm{Li}^{+}$ $<\mathrm{Na}^{+}<\mathrm{K}^{+}<\mathrm{Cs}^{+} .{ }^{11}$ Furthermore, spectator cations have been shown to alter the selectivity of aqueous $\mathrm{CO}_{2}$ reduction ${ }^{17}$ on $\mathrm{Cu}$ from $\mathrm{H}_{2}$ for $\mathrm{Li}^{+}$to $\mathrm{C}_{2} \mathrm{H}_{4}, \mathrm{C}_{2} \mathrm{H}_{5} \mathrm{OH}$ with $\mathrm{Cs}^{+} ;{ }^{17}$ and $\mathrm{CO}$ reduction toward $\mathrm{C}_{2} \mathrm{H}_{4}$ relative to $\mathrm{CH}_{4}$ from $\mathrm{Li}^{+}, \mathrm{Na}^{+}$, and $\mathrm{K}^{+}$

Received: June 21, 2021

Published: August 26, 2021 
to $\mathrm{Rb}^{+}$and $\mathrm{Cs}^{+}{ }^{18}$ All of these observations point to the possibility that the chemical physics of electrolytes offers promising opportunities to significantly change catalytic activity and selectivity by tuning noncovalent interactions and solvation environments at the electrified interface. However, the physical origin about how cation and $\mathrm{pH}$ modify the solvation environment at the electrified interface is not fully understood. Below, we focus on the state-of-the-art understanding for cation-dependent and $\mathrm{pH}$-dependent HER/ HOR kinetics.

Unfortunately, the physical origin of cation- and $\mathrm{pH}$ dependent HER/HOR kinetics is still under debate. Generally speaking, HER/HOR kinetics $\left(2 \mathrm{H}^{+}+2 e^{-} \leftrightarrow \mathrm{H}_{2}\right.$ in acid and $2 \mathrm{H}_{2} \mathrm{O}+2 e^{-} \leftrightarrow \mathrm{H}_{2}+2 \mathrm{OH}^{-}$in base) involve dissociative adsorption/desorption of $\mathrm{H}_{2}$ without electron transfer (Tafel step, $\left.2 \mathrm{H}_{\mathrm{ad}} \leftrightarrow \mathrm{H}_{2}+2^{*}\right)^{9,15,19}$ or with simultaneous electron transfer (Heyrovsky step, $\mathrm{H}_{\mathrm{ad}}+\mathrm{H}^{+}+e^{-} \leftrightarrow \mathrm{H}_{2}+*$ in acid and $\mathrm{H}_{\mathrm{ad}}+\mathrm{H}_{2} \mathrm{O}+e^{-} \leftrightarrow \mathrm{H}_{2}+\mathrm{OH}^{-}+*$ in base $)^{9,15,19}$ and the formation/oxidation of adsorbed hydrogen (Volmer step, $\mathrm{H}_{3} \mathrm{O}^{+}+e^{-}+* \leftrightarrow \mathrm{H}_{\mathrm{ad}}+\mathrm{H}_{2} \mathrm{O}$ in acid and $\mathrm{H}_{2} \mathrm{O}+e^{-}+* \leftrightarrow$ $\mathrm{H}_{\mathrm{ad}}+\mathrm{OH}^{-}$in base), ${ }^{15,19}$ whereby the asterisk represents an adsorption site on Pt. The Volmer step has been proposed as the rate-determining step (RDS) for HER/HOR kinetics on polycrystalline $\mathrm{Pt}$ surfaces based on some previous work by Gasteiger et al., ${ }^{15,19}$ Tang et al., ${ }^{20}$ Liu et al., ${ }^{21}$ and Koper et al. $^{10}$ On the other hand, other studies such as Chan et al. ${ }^{22}$ have shown that the activation energy of the Heyrovsky reaction was higher than that of the Volmer reaction on $\mathrm{Pt}(111)$ via density functional theory calculation, indicating that the Heyrovsky step is the RDS in HER. Thus, we are not able to exclude the possibility of the Heyrovsky step being the RDS.

There have been two schools of thought to explain the electrolyte-dependent activity for $\mathrm{HER} / \mathrm{HOR}^{23,24}$ First, the binding energy of surface absorbates ${ }^{8,9}$ has been reported to govern the kinetics of HER/HOR, which can be cation- ${ }^{11,25,26}$ and $\mathrm{pH}$-dependent. ${ }^{8,9}$ For example, hydrogen binding energy $(\mathrm{HBE})^{8,9}$ on precious metals (e.g., Pt, Ir, Pd, and Rh) has been estimated from hydrogen underpotential deposition regions of cyclic voltammograms (CVs), which is shown to increase linearly with increasing $\mathrm{pH}$ over a broad $\mathrm{pH}$ range $(0-13)$ and is correlated with decreasing HER/HOR kinetics. Later, Zheng et al. ${ }^{27}$ suggested to consider the disruption of water structure inevitably occurred during the Volmer step and thus proposed the concept of apparent $\mathrm{HBE}, \mathrm{HBE}_{\mathrm{app}}=\mathrm{HBE}+\Delta G_{\mathrm{IW}}^{0}$, where $\mathrm{HBE}$ is determined from the $\mathrm{H}$ adsorption/desorption peak in the $\mathrm{CV}$ and $\Delta G_{\mathrm{IW}}^{0}$ represents the Gibbs free energy change of the interfacial water during HER/HOR. Recent studies ${ }^{20,28}$ have questioned the extraction of HBE from peak shifts in the hydrogen underpotential deposition regions using $\mathrm{CV}$ measurements and thus raised questions regarding the applicability of the first school of thought. For example, cation-dependent peak shifts associated with hydrogen underpotential deposition on $\mathrm{Pt}(110)$ in base have been attributed to slow kinetics of $\mathrm{H}_{\mathrm{ad}}$ adsorption but not changes in the HBE. $^{20}$ In addition to $\mathrm{H}_{\mathrm{ad}}, \mathrm{OH}_{\mathrm{ad}}$ is reported recently to be coadsorbed with alkali cations on stepped Pt surfaces in the conventional hydrogen underpotential deposition region (0$\left.0.4 \mathrm{~V}_{\mathrm{RHE}}\right)$, ${ }^{28}$ where the adsorption energy of $\mathrm{OH}_{\mathrm{ad}}$ is shown to increase in the order of $\mathrm{Li}^{+}>\mathrm{Na}^{+}>\mathrm{K}^{+}>\mathrm{Cs}^{+}{ }^{11}$ The coadsorption of $\mathrm{H}_{\mathrm{ad}}$ and $\mathrm{OH}_{\mathrm{ad}}$ in a low potential region (0-0.4 $\mathrm{V}_{\mathrm{RHE}}$ ) implies that the peak shifts from hydrogen underpotential deposition regions ${ }^{8,14}$ might not be appropriate to extract the binding energy of $\mathrm{H}_{\mathrm{ad}}$ as the observed peak shifts can arise from coadsorption and interactions of alkali cations and $\mathrm{OH}_{\mathrm{ad}}$ on the step sites of $\mathrm{Pt}(553)$ instead of $\mathrm{pH}$ dependent HBE. ${ }^{28}$ The second school of thought has attributed such $\mathrm{pH}$-dependent kinetics to $\mathrm{pH}$-dependent reorganization energy of interfacial water molecules on $\mathrm{Pt}(111),{ }^{12}$ where faster kinetics in acid are associated with higher entropy with less ordered structure in acid as a result of lower potential of zero charge (PZC) and lower reorganization energy for interfacial water than those in base. This argument is in agreement with recent computational findings on $\mathrm{pH}$ dependent proton transfer barriers for HER/HOR kinetics, ${ }^{29}$ where greater $\mathrm{pH}$ is correlated with larger entropic barrier of proton transfer across the outer Helmholtz layer and thus lowered HER/HOR kinetics. Further support to the role of solvation environment on the reaction kinetics comes from our recent work, ${ }^{30}$ which shows that the kinetics of aqueous outersphere electron transfer $\left[\mathrm{Fe}(\mathrm{CN})_{6}\right]^{3-} /\left[\mathrm{Fe}(\mathrm{CN})_{6}\right]^{4-}$ reaction can be increased by 2 orders of magnitude by tuning noncovalent interactions associated with alkali cations in the electrolyte. Such cation-dependent kinetics have been attributed to cation-dependent coordination environments of the redox species at the electrified interface, whereby cations of lower charge density such as $\mathrm{Cs}^{+}$(compared to $\mathrm{Li}^{+}$) in the redox solvation shell are associated with lower effective static dielectric constant at the interface, smaller reorganization energy, and greater kinetics. Therefore, it is of great interest to examine cation- and $\mathrm{pH}$-dependent HER/HOR kinetics using the Marcus-Hush-Chidsey (MHC) framework and surfaceenhanced infrared absorption spectroscopy (SEIRAS), from which new insights into the role of noncovalent interactions and/or interfacial solvation environments on the HER/HOR kinetics can be obtained.

In this study, we employed a series of structure-making/ breaking cations in aqueous electrolytes of $\mathrm{pH} 1$ to 14 to perturb the interfacial structure at polycrystalline $\mathrm{Pt}$ and investigate the kinetics of $\mathrm{HER} / \mathrm{HOR}$. Classical molecular dynamics (MD) simulation showed that structure-making cations (e.g., $\mathrm{Li}^{+}$and $\mathrm{Na}^{+}$) retained their solvation shell at the electrified interface, while structure-breaking cations (e.g., $\mathrm{Rb}^{+}$ and $\mathrm{Cs}^{+}$) exhibited a tendency to partially desolvate and segregate to the surface, where such a cation-dependent interfacial structure was more significant at $\mathrm{pH} 13$ than at $\mathrm{pH} 1$ due to higher negative surface charge at $\mathrm{pH} 13$ as a result of higher PZC (1.1 $\mathrm{V}_{\mathrm{RHE}}$ for the $\mathrm{Pt}(111)$ surface) at $\mathrm{pH} 13$ than that at $\mathrm{pH} 1\left(0.3 \mathrm{~V}_{\mathrm{RHE}}\right.$ for the $\mathrm{Pt}(111)$ surface $){ }^{31}$ The exchange current density of HER/HOR increased by up to 2 orders of magnitude with greater structure-making tendency in the order of $\mathrm{Cs}^{+}<\mathrm{Rb}^{+}<\mathrm{K}^{+}<\mathrm{Na}^{+}<\mathrm{Li}^{+}$, which was accompanied by decreasing reorganization energy extracted from MHC analysis. Such cation-dependent exchange current density and reorganization energy trends became more pronounced with increasing $\mathrm{pH}$. We propose that partial desolvation and concentration of cations with increasing structure-breaking tendency (such as $\mathrm{Cs}^{+}$) at the electrified interface results in higher static dielectric constants at the interface, greater reorganization energy and higher entropic barrier associated with the formation of $\mathrm{H}_{\mathrm{ad}}$ from $\mathrm{H}_{2} \mathrm{O}$, and reduced HER/HOR kinetics. Such molecular-level understanding sheds new insights on electrolyte engineering as an alternative pathway to control electrochemical reaction kinetics. 


\section{METHODS}

\section{Classical Molecular Dynamics Simulations}

To isolate the effect of $\mathrm{pH}$ on the cation-electrode binding affinity, we set up a series of simulations of an aqueous electrolyte solution of $\mathrm{Cl}^{-}$and alkali ions $\left(\mathrm{Li}^{+}, \mathrm{Na}^{+}, \mathrm{K}^{+}, \mathrm{Rb}^{+}, \mathrm{Cs}^{+}\right)$confined between platinum electrodes at constant potential of $-0.3 \mathrm{~V}$ and at $-1.1 \mathrm{~V}$ relative to $\mathrm{PZC}$ for the $\mathrm{Pt}(111)$ surface, corresponding to $0 \mathrm{~V}_{\mathrm{RHE}}$ at $\mathrm{pH} 1$ and $\mathrm{pH} 13$, respectively. As we study the negative charged $\mathrm{Pt}(111)$ surface, cations were expected to interact with the surface by Coulombic interaction. Due to limited validation of the force field parameters of $\mathrm{ClO}_{4}{ }^{-}$and $\mathrm{OH}^{-}$anions, $\mathrm{Cl}^{-}$anions were considered to replace $\mathrm{ClO}_{4}^{-}$for simulating acidic solutions and $\mathrm{OH}^{-}$for simulating alkaline solutions. All of the simulations were performed in LAMMPS. A simulation box with dimensions of $30.43 \times 28.75 \times 89.23 \AA$ was periodically replicated in $x, y$-directions, while a fixed boundary condition was employed for the $z$-direction containing the platinum electrode. The simulation box contained $792 \mathrm{Pt}$ atoms, 2293 water molecules, and 42 alkali ions with an equal amount of $\mathrm{Cl}^{-}$anion as their counterions, approximately corresponding to a $1 \mathrm{M}$ concentration of cations. Due to the lack of appropriate force field parameter to describe proton and hydroxyl in the literature, $\mathrm{Cl}^{-}$ions were used as counterions to balance the charge of alkali metal cations for both $\mathrm{pH} 1$ and $\mathrm{pH}$ 13. The long-range electrostatic interactions ${ }^{32}$ were calculated using a particle-mesh Ewald algorithm with a real-space cutoff value of $9 \AA$. An NVT ensemble with a Langevin thermostat was employed to keep the system at $300 \mathrm{~K}$. A Langevin thermostat was used here as we were only concerned with the static properties of the system at equilibrium. Furthermore, the Shake algorithm ${ }^{33}$ was used to constrain the bonds and angles of SPC/E water. The system was equilibrated for $0.1 \mathrm{~ns}$ before performing the final production runs of $1 \mathrm{~ns}$ with a time step of $2 \mathrm{fs}$ using the SPC/E force field for water. Lennard-Jones (LJ) parameters were used along with the scaled ionic charge model for alkali ions in order to account for electronic polarization effects in a classical nonpolarizable force field. LorentzBerthelot mixing rules were employed to derive the mixed LJ parameters. The $\mathrm{Pt}(111)$ electrode atoms were modeled using the LJ force field from ref 34 . The charges on each platinum atom were calculated at each time step to satisfy the imposed voltage across the cell (either 0.3 or $1.1 \mathrm{~V}$ ) by the constant potential fix in LAMMPS developed by Wang et al. ${ }^{35}$ All of the parameters used are summarized in Table S1. Note that our MD simulation system did not include the presence of $\mathrm{H}_{\mathrm{ad}}$ on the Pt surface at $0 \mathrm{~V}_{\mathrm{RHE}}$. As a result, the simulations are of limited quantitative value. However, we assume that qualitative trends that emerge when changing cation identity are physically meaningful. While our simulations did not include the potential difference in the relative surface hydrophobicity, or the associated changes in the double layer water structure, the free energy differences in the cation desolvation responsible for the cationdependent trends in interfacial structure were expected to be similar for both hydrophilic (without $\mathrm{H}_{\mathrm{ad}}$ ) and hydrophobic (with $\mathrm{H}_{\mathrm{ad}}$ ) surfaces as a cation-dependent interfacial water structure on a hydrophobic surface (CO-covered $\mathrm{Pt}$ ) has also been reported previously. ${ }^{36}$ While the exact interfacial water structure in our MD simulation might be different from the realistic condition, our MD simulation results via the simplified model are supported by our reorganization energy, reaction entropy, and in situ SEIRAS experiments. Further study by considering $\mathrm{H}_{\mathrm{ad}}$ on the Pt surface in MD simulations is needed to provide more quantitative information.

\section{Electrochemical Measurements and Electrolyte}

\section{Preparation}

A Biologic SP-300 potentiostat and a three-electrode electrochemical system $^{37}$ were employed for all electrochemical measurements. A Pt rotating disk electrode ( $\mathrm{RDE}$ ) (Pine Instrument) was used as the working electrode. Potentials were recorded versus a mercury sulfate $\left(\mathrm{Hg} / \mathrm{HgSO}_{4}\right)$ reference electrode in acidic and buffer solutions and to a mercury oxide $(\mathrm{Hg} / \mathrm{HgO})$ reference electrode in alkaline electrolytes. All potentials were converted to the RHE scale. The effects of $\mathrm{pH}$ and cations on $\mathrm{H} / \mathrm{OH}$ adsorption/desorption and the kinetics of
HER/HOR were examined by CV measurements at a scan rate of 50 $\mathrm{mV} \mathrm{s}^{-1}$ in Ar-saturated electrolytes and $10 \mathrm{mV} \mathrm{s}^{-1}$ in $\mathrm{H}_{2}$-saturated solutions at $293 \mathrm{~K}$. The normalized current density was obtained using the geometric surface area of $\operatorname{RDE}\left(0.196 \mathrm{~cm}^{2}\right)$, and the reported potentials were $i R$ corrected. For temperature-dependent measurements, the cell temperature was controlled by a thermal bath circulator (Thermo Neslab RTE 7) and increased from 293 to $323 \mathrm{~K}$ in increments of $10 \mathrm{~K}$. Buffer solutions and acidic and alkaline electrolytes were prepared from deionized water (Millipore, $>18.2$ $\mathrm{M} \Omega . \mathrm{cm}$ ). For cation-dependent measurements, $0.1 \mathrm{M}$ perchlorate salt of $\mathrm{Li}^{+}, \mathrm{Na}^{+}$, or $0.08 \mathrm{M}$ perchlorate salt of $\mathrm{K}^{+}, \mathrm{Cs}^{+}$or $0.05 \mathrm{M}$ perchlorate salt of $\mathrm{Rb}^{+}$were added to electrolyte at $\mathrm{pH} 1$ and $\mathrm{pH} 2$ prepared by diluting $\mathrm{HClO}_{4}$ (Sigma-Aldrich 70 wt \%). Alkaline electrolytes at $\mathrm{pH} 12-14$ were prepared with aqueous solutions of 0.01-1 M lithium hydroxide (Sigma-Aldrich 99.9\%), sodium hydroxide (Sigma-Aldrich 99.9\%), potassium hydroxide (SigmaAldrich 99.95\%), rubidium hydroxide (Sigma-Aldrich 99.95\%), and cesium hydroxide (Sigma-Aldrich $99.95 \%$ ). The purity of cesium hydroxide was further analyzed by inductively coupled plasma (Table S2). Buffer solutions were prepared by adding different amounts (e.g., 1 and $2 \mathrm{~mL}$ ) of $4 \mathrm{M}$ hydroxide of $\mathrm{Li}^{+}, \mathrm{Na}^{+}, \mathrm{K}^{+}, \mathrm{Rb}^{+}$, and $\mathrm{Cs}^{+}$into 50 $\mathrm{mL}$ of $0.2 \mathrm{M}$ solution of phosphoric acid (Sigma-Aldrich $80 \mathrm{wt} \%$ ), citric acid (Sigma-Aldrich 99.9\%), acetic acid (Sigma-Aldrich 99.9\%), bicarbonate (Sigma-Aldrich 99.9\%), and carbonate (Sigma-Aldrich 99.9\%).

For the extraction of kinetic current density, we measured HER/ HOR polarization curves with $\mathrm{Pt} \mathrm{RDE}$ at rotation speeds from 400 to $2500 \mathrm{rpm}$, as shown in Figure S1a-c. Kinetic current density could be estimated from rotation speed dependent HOR polarization curves using the Koutechy-Levich equation. ${ }^{38}$ (Further details can be found in Supporting Information and in our previous work. ${ }^{30}$ )

To extract kinetic parameters, including the exchange current density and reorganization energy, from kinetic current density, the Butler-Volmer equation and MHC formalism ${ }^{39,40}$ were employed. The MHC formalism, widely employed to accurately predict activity trends of numerous Faradaic reaction kinetics, including inner-sphere and outer-sphere reactions, for example, PCET reactions (HER/HOR on nickel-based molecular electrocatalyst ${ }^{41}$ and the reduction of water-superoxide ion complex on a glassy carbon electrode ${ }^{42}$ ), interfacial ET on the metal surfaces, ${ }^{30}$ lithium electrodeposition/ stripping, ${ }^{43}$ and lithium-ion intercalation at solid-solid interfaces, ${ }^{40,44}$ considers the reactant-solvent interactions but not the reactantelectrode interactions (Appendix S1), which can be used to describe the HER/HOR kinetics on $\mathrm{Pt}$ as the hydration energy of the proton $(-11.5 \mathrm{eV})^{45}$ is 2 orders of magnitude larger than that with HBE on Pt $(-0.1 \mathrm{eV}) .{ }^{46}$ This hypothesis is supported by the fact that the values of exchange current density extracted by MHC formalism (Figure S2a,c) are comparable to those extracted via the ButlerVolmer equation (Figure S2b,c). Further support comes from the fact that the value of the reorganization energy of the Volmer reaction on a metal surface has been reported to be $\sim 0.4 \mathrm{eV},{ }^{47}$ which is comparable to the cation-dependent reorganization energy found in this work, $0.6-1.2 \mathrm{eV}$. Therefore, based on our understanding from the literature ${ }^{42,48-50}$ and the consistency between our results and previous work, ${ }^{8,47}$ we propose that the kinetics of HER/HOR on $\mathrm{Pt}$ $\mathrm{RDE}$ can be described by the MHC formalism. (More details can be found in Supporting Information and in our previous work. ${ }^{30}$ )

\section{In Situ Surface-Enhanced Infrared Absorption} Spectroscopy

A hemispherical Si prism (radius $22 \mathrm{~mm}$, Pier Optics) deposited with $\mathrm{Pt}$ was mounted in a spectro-electrochemical three-electrode cell. The reference electrode used was a mercury oxide electrode, and a platinum wire was used as the counter electrode. A Fourier transform infrared (FTIR) Vertex 70 (Bruker) spectrometer equipped with an MCT detector was used to record SEIRAS spectra. Additional experimental details for the in situ SEIRAS measurements can be found elsewhere. ${ }^{51,52}$ For in situ SEIRAS measurements during HER/ HOR in electrolyte at $\mathrm{pH} 13$, electrolytes consisting of $0.1 \mathrm{M}$ hydroxide of $\mathrm{Li}^{+}, \mathrm{K}^{+}$, and $\mathrm{Cs}^{+}$were saturated with $\mathrm{H}_{2}$ by purging $\mathrm{H}_{2}$ 
a)

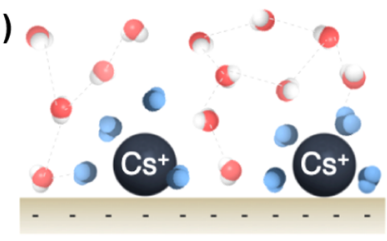

b)

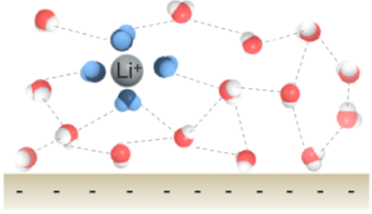

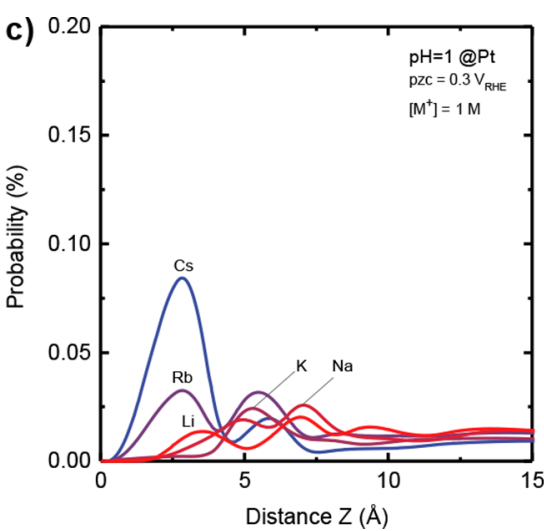

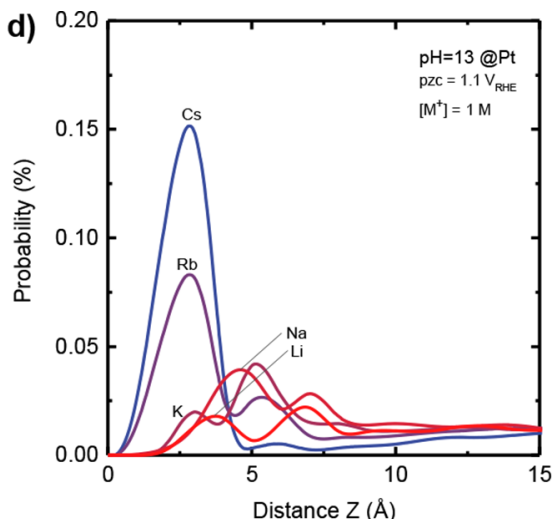

Figure 1. Tuning the outer Helmholtz layer (OHL) structure at the electrode/electrolyte interface by spectator ions contained in the electrolyte. Schematic illustration showing the interactions among interfacial water molecules, cation, and the interface where (a) water molecules are removed from the interface by larger cations $\left(\mathrm{Cs}^{+}\right)$due to strong ion-surface interaction and (b) stable interfacial water layer in the presence of smaller cations $\left(\mathrm{Li}^{+}\right)$. Strongly H-bonded (ice-like) and asymmetric $\mathrm{H}$-bonded (solvating ion) water molecules are represented in red and blue, respectively. The $z$-axial probability distribution function (ZDF) of the surface cation in a classical MD simulation of $\mathrm{Pt}(111)$ for $(\mathrm{c}) \mathrm{pH} 1$ at 0 $\mathrm{V}_{\mathrm{RHE}}, 0.3 \mathrm{~V}$ lower than the potential of zero charge $(\mathrm{PZC})$ and $(\mathrm{d}) \mathrm{pH} 13$ at $0 \mathrm{~V}_{\mathrm{RHE}}, 1.1 \mathrm{~V}$ lower than PZC, where the unit cells contain 2293 water molecules, 42 cations, $42 \mathrm{Cl}^{-}$anions, corresponding to $1 \mathrm{M}$ cation in water.
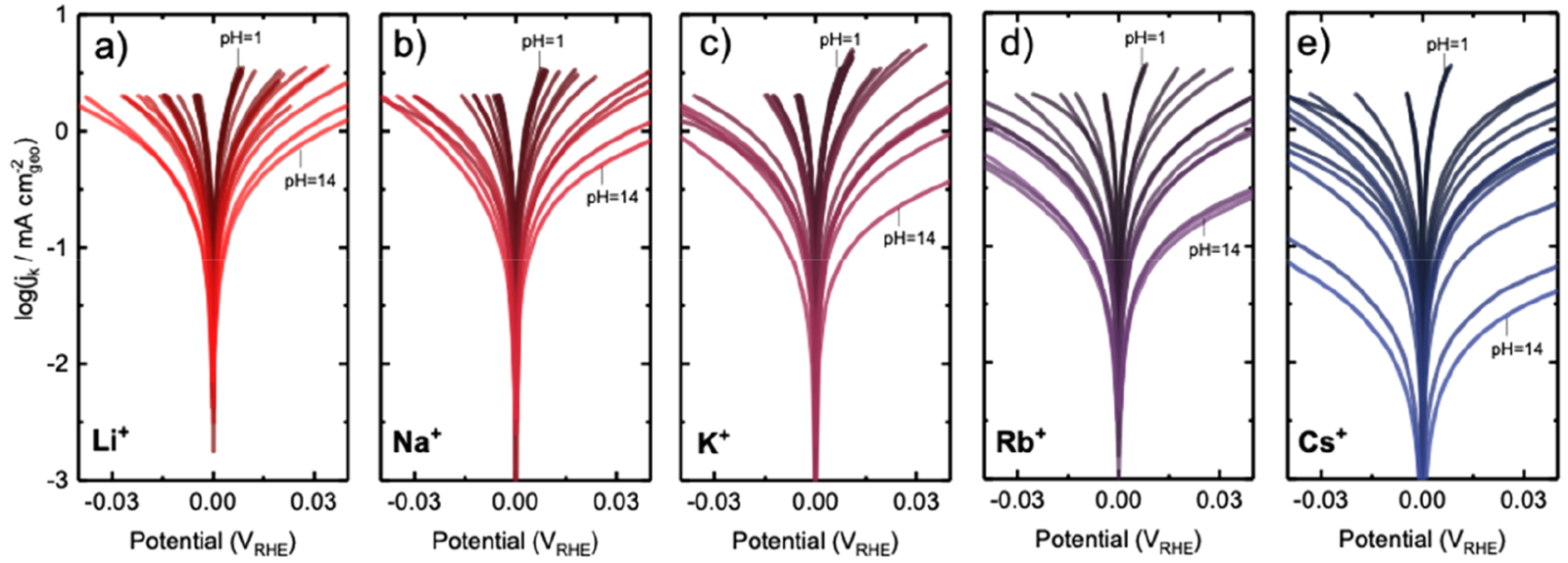

Figure 2. Cation-dependent and $\mathrm{pH}$-dependent HER/HOR kinetics on Pt RDE electrode in $\mathrm{H}_{2}$-saturated aqueous electrolytes of $0.01-0.1 \mathrm{M}$ $\mathrm{HClO}_{4}$ with $0.05-0.1 \mathrm{M}$ perchlorate salts of $\mathrm{Li}, \mathrm{Na}, \mathrm{K}, \mathrm{Rb}$, and $\mathrm{Cs}(\mathrm{pH} 1-2)$, buffer solutions consisting $0.2 \mathrm{M}$ of acetic acid ( $\left.\mathrm{pH} 2-4\right)$, citric acid ( $\mathrm{pH} 1-3)$, phosphoric acid ( $\mathrm{pH} 1-13)$, bicarbonate ( $\mathrm{pH}$ 8-10), carbonate $(\mathrm{pH} 11-12)$ with $0.2 \mathrm{M} \mathrm{MOH}(\mathrm{M}=\mathrm{Li}, \mathrm{Na}, \mathrm{K}, \mathrm{Rb}$ and $\mathrm{Cs})$, and aqueous solutions of the hydroxide of $\mathrm{Li}, \mathrm{Na}, \mathrm{K}, \mathrm{Rb}$, and $\mathrm{Cs}$ for $\mathrm{pH} 12-14$. Kinetic current density of HER/HOR on Pt RDE electrode in aqueous electrolytes containing (a) $\mathrm{Li}^{+}$, (b) $\mathrm{Na}^{+}$, (c) $\mathrm{K}^{+}$, (d) $\mathrm{Rb}^{+}$, and (e) $\mathrm{Cs}^{+}$at $\mathrm{pH}$ from 1 to 14 .

gas. Before in situ SEIRAS measurements, the prism surface was cleaned by cycling the potential between 0.05 and $1.1 \mathrm{~V}_{\mathrm{RHE}}$. SEIRAS spectra were collected at a potential from 1.1 to $-0.3 \mathrm{~V}_{\mathrm{RHE}}$ at room temperature. The reference spectrum $I_{0}$ was measured at $1.1 \mathrm{~V}_{\mathrm{RHE}}$. All spectra are shown in absorbance units defined as $\log \left(I_{0} / I\right)$, where $I_{0}$ and $I$ represent the spectra at the reference and sample potentials, respectively. We note that the same $\mathrm{Pt}$ surface was used for measurements in $0.1 \mathrm{M} \mathrm{LiOH}, \mathrm{KOH}$, and $\mathrm{CsOH}$ to ensure a similar surface enhancement effect.

\section{RESULTS AND DISCUSSION}

\section{pH-Dependent and Cation-Dependent Solvation} Environments at the Electrified Interface from MD

Our MD simulation results show that the solvation environment of redox anions and cations at the electrified interface induced by noncovalent interactions is cation dependent. With larger cations (e.g., $\mathrm{Cs}^{+}$), there are fewer surface water molecules (having been replaced by cations), as illustrated in Figure 1a, whereby with smaller cations (e.g., $\mathrm{Li}^{+}$), the surface layer is primarily water molecules, as illustrated in Figure $1 b$.
The $z$-axial probability distribution functions (ZDF) for surface cations from classical MD simulations for $\mathrm{pH} 1$ (Figure 1c) and $\mathrm{pH} 13$ (Figure 1d) revealed increasing peak intensity in the order of $\mathrm{Li}^{+}<\mathrm{Na}^{+}<\mathrm{K}^{+}<\mathrm{Rb}^{+}<\mathrm{Cs}^{+}$, corresponding to more structure-breaking cations $\left(\mathrm{Cs}^{+}\right)$in the vicinity of the electrified interface than structure-making cations $\left(\mathrm{Li}^{+}\right)$. In addition, the peak center for larger cations such as $\mathrm{Cs}^{+}$and $\mathrm{Rb}^{+}$ was found to be $2.8 \AA$ compared to $\sim 4 \AA$ for that of smaller cations such as $\mathrm{Li}^{+}$and $\mathrm{Na}^{+}$, indicating that $\mathrm{Rb}^{+}$and $\mathrm{Cs}^{+}$are partially desolvated at the electrified interface, whereas $\mathrm{Li}^{+}$and $\mathrm{Na}^{+}$(assembled $>3 \AA$ from the surface) retain their solvation shell at the electrified interface. This difference can be attributed to stronger Coulombic interactions with the negatively charged surface with larger cations (e.g., $\mathrm{Cs}^{+}$) having less tightly bound water in the solvation shell ${ }^{36,53}$ (Figure 1a) than those of smaller cations (e.g., $\mathrm{Li}^{+}$) with tightly bound hydration shells (Figure 1b). Moreover, $\operatorname{Pt}(111$ ) exhibits higher PZC $\left(\sim 1.1 \mathrm{~V}_{\mathrm{RHE}} \text { at } \mathrm{pH} 13\right)^{31,54}$ in base than in acid $\left(\sim 0.3 \mathrm{~V}_{\mathrm{RHE}}\right.$ at $\left.\mathrm{pH} 1\right) ; ;^{31,54}$ consequently, the electrified interface could electrostatically attract more cations to its 

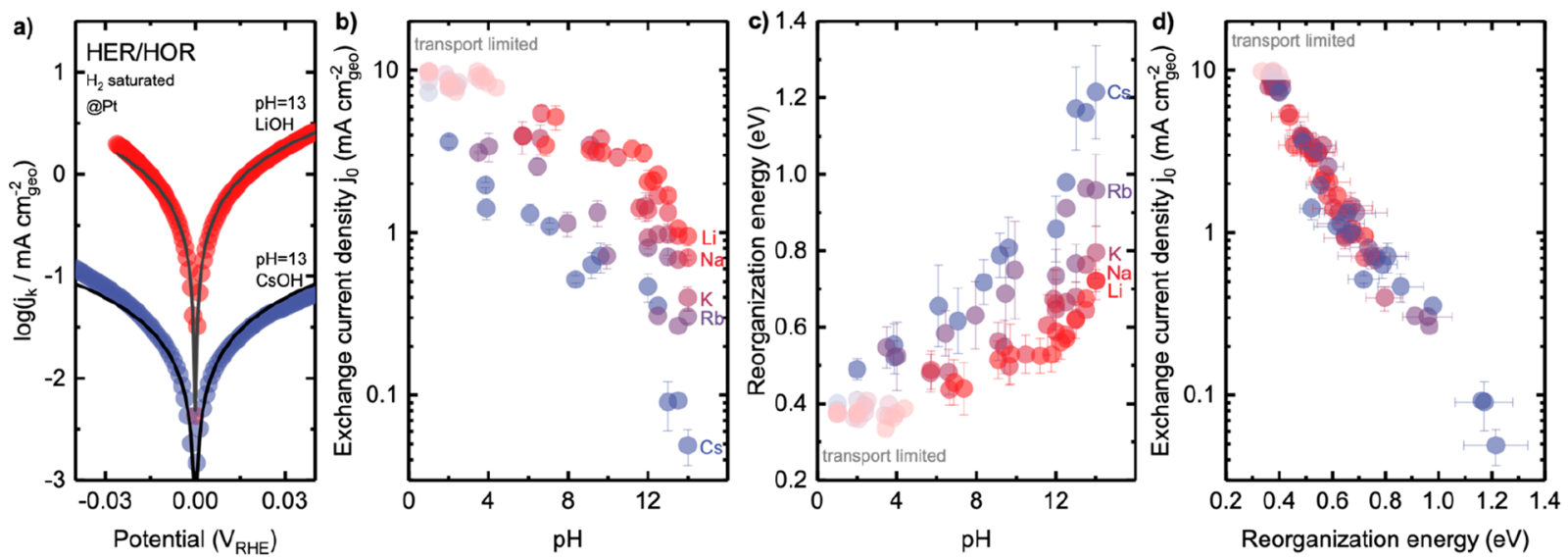

Figure 3. Extraction of reorganization energy of HER/HOR on Pt electrode from MHC formalism $j_{\text {red/ox }}^{\mathrm{MHC}}(\eta)=A \int_{-\infty}^{\infty} \exp \left(-\frac{(x-\lambda \pm \eta \eta)^{2}}{4 \lambda k_{\mathrm{B}} T}\right) \frac{\mathrm{d} x}{1+\exp \left(x / k_{\mathrm{B}} T\right)}$, where $\lambda$ is reorganization energy, $k_{\mathrm{B}}$ is the Boltzmann constant, $T$ is temperature, $\eta$ is the overpotential, $A$ is the pre-exponential factor, accounting for the electronic coupling strength and the electronic density of states (DOS) of the electrode, and $x$ accounts for the Fermi statistic of electron energies distributed around electrode potential. (a) Fitting of kinetic currents of HER/ HOR measured on the Pt surface in $0.1 \mathrm{M} \mathrm{LiOH}$ ( $\mathrm{pH} \mathrm{13}$, red circle) and in $0.1 \mathrm{M} \mathrm{CsOH}$ ( $\mathrm{pH} 13$, blue circle) by MHC formalism (black lines). Cation-dependent and $\mathrm{pH}$-dependent (b) exchange current density and (c) reorganization energy extracted by MHC formalism. (d) Exchange current density plotted against reorganization energy. Mass transport limitation in $\mathrm{RDE}$ measurements underestimates the exchange current density $>\sim 6 \mathrm{~mA} \mathrm{~cm}$ geo, which is shaded. Error bars were obtained from the standard deviation of 2-3 independent measurements. Full data points are available in Figure S6.

surface in base than in acid. In addition, the findings are in agreement with our previous observations that cations only exerted short-range effects on the water structure in their solvation shells and could not affect the hydrogen-bonding network in the bulk solution of $0.6 \mathrm{M}$ chloride with $\mathrm{Li}^{+}, \mathrm{Na}^{+}$, $\mathrm{K}^{+}, \mathrm{Rb}^{+}$, and $\mathrm{Cs}^{+},{ }^{30}$ unlike those reported for superconcentrated electrolytes such as $21 \mathrm{M}$ LiTFSI water-in-salt electrolyte. $^{55}$ Further support comes from surface X-ray scattering results on the $\operatorname{Pt}(111)$ surface in the presence of $\mathrm{Ba}^{2+}$ ions, which show that, relative to the $\mathrm{Pt}(111)$ surface, $\mathrm{Ba}^{2+}$ is found to be located at a distance larger than its ionic radii but smaller than the corresponding hydrated radii, suggesting that $\mathrm{Ba}^{2+}$ is partially dehydrated and immobilized at the interfaces by noncovalent interaction between $\mathrm{Ba}^{+}$and $\mathrm{OH}_{\mathrm{ad} \cdot}{ }^{56}$ In the next section, we discuss the HER/HOR kinetics measured near equilibrium $\left(0 \mathrm{~V}_{\mathrm{RHE}}\right)$, where the surface is dominant by $\mathrm{H}_{\mathrm{ad}}$ with $\mathrm{OH}_{\mathrm{ad}}$ coverage ${ }^{57}$ significantly lower than that in the $\mathrm{OH}$ adsorption region related previously to cationdependent HOR kinetics. ${ }^{11}$ We further correlate HER/HOR kinetics with interfacial solvation environment changes induced by cations in the electrolyte.

\section{pH- and Cation-Dependent Exchange Current Density of HER/HOR}

RDE measurements showed that the HER/HOR kinetic current densities were strongly dependent on $\mathrm{pH}$ (Figure 2), decreasing considerably with increasing $\mathrm{pH}$, and cationdependent, decreasing in the sequence of $\mathrm{Li}^{+}>\mathrm{Na}^{+}>\mathrm{K}^{+}>$ $\mathrm{Rb}^{+}>\mathrm{Cs}^{+}$in base, as shown in Figure 2. CVs of $\mathrm{H}_{2}$-saturated $0.1 \mathrm{M} \mathrm{LiOH}$ collected from Pt RDE revealed a well-defined kinetics-limiting regime (overpotential of $\pm 30 \mathrm{mV}$ ) and a linear increase in transport-limiting currents with increasing rotation speeds from 400, 900, 1600 to $2500 \mathrm{rpm}$ at $293 \mathrm{~K}$ in Figure S1a,d, from which kinetic currents were extracted using the Koutecky-Levich method. The kinetic current densities normalized by the geometric surface area $\left(0.196 \mathrm{~cm}^{2}\right)$ of $\mathrm{Pt}$ $\mathrm{RDE}$ are shown in Figure 2. Similar cation dependency was also observed for kinetic current densities normalized by the
ECSA (Figure S3). Comparable exchange current densities were obtained from fitting kinetic current densities, $\left(j_{0}\right)$ using the Butler-Volmer (Figure S2b,c) or the MHC formalism ${ }^{39,50}$ (Figure S2a,c). The extraction of kinetics current in acid is not accurate as the HOR kinetics on Pt are too fast to be separated from the hydrogen diffusion overpotential in RDE measurements. ${ }^{9,16}$ The measurements of HOR kinetics at $\mathrm{pH} 0$ has shown to be $\sim 2$ orders of magnitude higher than that at $\mathrm{pH} 13$ from the RDE measurement. ${ }^{14}$ The measured HOR current density at $2500 \mathrm{rpm}$ and $293 \mathrm{~K}$ after $i R$ correction and the calculated Nernstian diffusion overpotential $\left(\eta_{\text {diff }}\right)^{16}$ were compared at different $\mathrm{pH}$ with various cations in Figure S4, where the HER/HOR kinetics current densities in electrolytes at $\mathrm{pH}<6.9$ for $\mathrm{Li}^{+}$(Figure S4d) and $\mathrm{pH}<3.9$ for $\mathrm{Cs}^{+}$(Figure S4i) are indistinguishable from the Nernstian diffusion overpotential. Therefore, we focus on the HER/HOR kinetic data with exchange current density $j_{0}$ below $6 \mathrm{~mA} \mathrm{~cm}$ geo from RDE measurements, which are not limited by diffusion.

The exchange current density $j_{0}$ was found to decrease sharply with increasing $\mathrm{pH}$ by 2 orders of magnitude, where the dependence on $\mathrm{pH}$ became more pronounced in the order from $\mathrm{Li}^{+}, \mathrm{Na}^{+}, \mathrm{K}^{+}, \mathrm{Rb}^{+}$, to $\mathrm{Cs}^{+}$. The highest exchange current density $\left(9.9 \pm 0.6 \mathrm{mAcm} \mathrm{cm}_{\text {geo }}^{-2}\right)$ was obtained for $\mathrm{Li}^{+}$at $\mathrm{pH} 1$ whereas the lowest $(0.05 \pm 0.01 \mathrm{~mA} \mathrm{~cm}$ geo $)$ was found for $\mathrm{Cs}^{+}$ at $\mathrm{pH} 14$ (Figure $3 \mathrm{~b}$ ). The values of exchange current density were in agreement with a previous RDE study, ${ }^{9,16}$ for example, $\sim 8.2 \pm 0.6 \mathrm{~mA} \mathrm{~cm}_{\text {geo }}^{-2}$ at $\mathrm{pH} 2$ in citrate buffer with $\mathrm{K}^{+}(\sim 6 \mathrm{~mA}$ $\left.\mathrm{cm}_{\mathrm{pt}}^{-29}\right)$ and $\sim 0.9 \pm 0.1 \mathrm{~mA} \mathrm{~cm}-2$ geo at $\mathrm{pH} 13$ in $0.1 \mathrm{M} \mathrm{KOH}(0.7$ $\left.\mathrm{mA} \mathrm{cm}_{\text {geo }}^{-216}\right)$. The exchange current density at $\mathrm{pH} 13$ was strongly cation-dependent, having $1.6 \pm 0.2 \mathrm{~mA} \mathrm{~cm}$ geo in $0.1 \mathrm{M}$ $\mathrm{LiOH}$ to $0.1 \pm 0.03 \mathrm{~mA} \mathrm{~cm}$ geo in $0.1 \mathrm{M} \mathrm{CsOH}$ (Figure $3 \mathrm{a}, \mathrm{b}$ and Figure S5 for cation-dependent kinetic current density). The extracted exchange current density at $\mathrm{pH} 1$ was not significantly cation-dependent (Figure $3 b$ and Figure S5), which can be attributed to the mass transport limitation as mentioned above. These differences can be attributed to the interaction of cations with water molecules around them, 

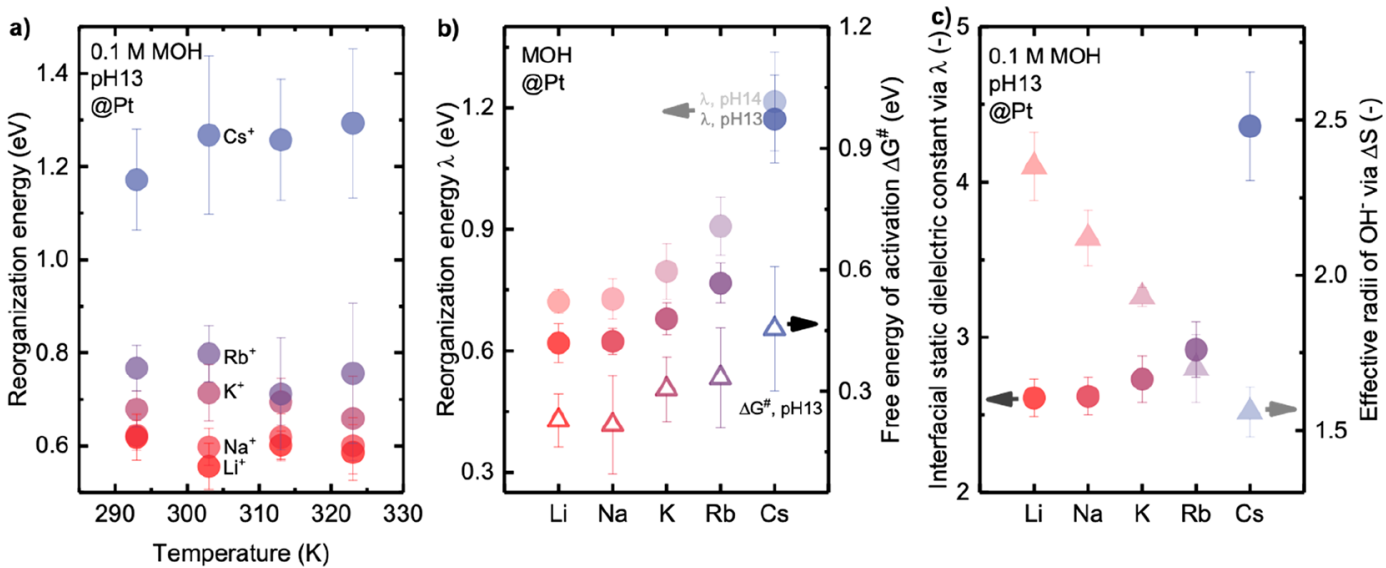

Figure 4. Fitting temperature-dependent kinetics of HER/HOR on Pt RDE in alkaline electrolytes using the MHC formalism: (a) reorganization energy measured at $\mathrm{pH} 13$ in $0.1 \mathrm{M}$ hydroxide of $\mathrm{Li}^{+}, \mathrm{Na}^{+}, \mathrm{K}^{+}, \mathrm{Rb}^{+}$, and $\mathrm{Cs}^{+}$for a temperature range from 293 to $323 \mathrm{~K}$; (b) comparison of reorganization energy of HER/HOR at $\mathrm{pH} 13$ and $\mathrm{pH} 14$ by the MHC formalism, and the free energy of activation $\Delta G^{\ddagger}$ for $\mathrm{HER} / \mathrm{HOR}$ at $\mathrm{pH} 13$ obtained by Arrhenius analysis; (c) cation-dependent interfacial static dielectric constant of water extracted by Born model of reorganization energy and effective radii of $\mathrm{OH}^{-}$fitted using Born model of reaction entropy. Error bars were obtained from the standard deviation of 2-3 independent measurements. Full data points of reorganization energy at $\mathrm{pH} 13$ are available in Figure S9.

where smaller cations with higher charge density (e.g., $\mathrm{Li}^{+}$and $\mathrm{Na}^{+}$) tend to interact strongly with neighboring water molecules, ${ }^{53,58}$ while larger ions (e.g., $\mathrm{Cs}^{+}$and $\mathrm{Rb}^{+}$) impose weaker constraints on their solvation shells. ${ }^{53,58}$

In this work, we assign the cation-dependent exchange current density of HER/HOR kinetics to the cation-dependent Volmer $^{15,19}$ or Heyrovsky ${ }^{22}$ step, where having larger cations at the electrified interface compared to smaller cations impedes water dissociation associated in the Volmer or Heyrovsky step in a base. Having a Volmer rate-determining step is supported by the experimental values of the Tafel slope being $\sim 120 \mathrm{mV}$ $\operatorname{dec}^{-1}$ (Figure S7), which is in agreement with that estimated from $\frac{R T}{\alpha F} 59$ (with $\alpha=0.5$ ). Further support comes from fitting kinetic current densities to the Butler-Volmer or the MHC formalism with $\alpha_{\mathrm{a}}+\alpha_{\mathrm{c}}=1$, suggesting that HER/HOR reactions undergoes the Tafel-Volmer mechanism but not the Heyrovsky-Volmer mechanism having $\alpha_{\mathrm{a}}+\alpha_{\mathrm{c}}=2 .{ }^{19}$ On the other hand, Intikhab et al. ${ }^{20}$ showed that the kinetics of water dissociation (Volmer reaction) were slower in $\mathrm{LiOH}$ than in $\mathrm{KOH}$ electrolyte, whereas HER/HOR was faster in $\mathrm{LiOH}$ than in $\mathrm{KOH}$ electrolyte, ${ }^{57}$ indicating that the Volmer reaction was not the RDS and either the Heyrovsky or Tafel step should be limiting. We attributed the cation dependence of exchange current densities to changes in the solvation structure at the electrified interface associated with noncovalent interactions among cations, water molecules, and $\mathrm{Pt}$, which is supported by cation-dependent interfacial structure from $\mathrm{MD}$ simulation shown in Figure 1. Specifically, cations could alter the interfacial solvation structure and its reorganization, and the energetic barrier associated with proton-coupled electron transfer in the Volmer or Heyrovsky step, which would lead to cation-dependent HER/HOR kinetics. In the next section, we further extracted the reorganization energy of HER/HOR kinetics using the MHC formalism and discussed its physical origin and implication.

\section{pH- and Cation-Dependent Reorganization Energy}

The reorganization energy for the HER/HOR kinetics was found to be cation-dependent, increasing with larger cations or greater structure-breaking tendency, as shown in Figure 3c. The reorganization energy was found to increase from $0.46 \pm$
0.06 to $0.72 \pm 0.03 \mathrm{eV}$ for $\mathrm{Li}^{+}$with increasing $\mathrm{pH}$ from 6.9 to 14 , while a greater increase from $0.52 \pm 0.04$ to $1.22 \pm 0.12 \mathrm{eV}$ was noted for $\mathrm{Cs}^{+}$with increasing $\mathrm{pH}$ from 3.9 to 14 . Similar trends were observed for the other cations. The exchange current density predicted by the MHC formalism (eq S5) was found to decrease linearly with increasing reorganization energy (Figure 3d).

Fitting temperature-dependent kinetics of HER/HOR at $\mathrm{pH}$ 13 with increasing temperature from 293 to $323 \mathrm{~K}$ (Figure S8a-e) using the MHC formalism revealed that the reorganization energy was temperature-independent (Figure $4 a)$. Moreover, the free energy of activation obtained from the Arrhenius analysis of temperature-dependent exchange current densities of HER/HOR (Figures $\mathrm{S} 8 \mathrm{f}-\mathrm{j}$ ) was found to be cation-dependent, increasing from $0.23 \pm 0.11 \mathrm{eV}$ for $\mathrm{Li}^{+}$to $0.46 \pm 0.25 \mathrm{eV}$ for $\mathrm{Cs}^{+}$(Figure 4b), which could be approximated as $\frac{\lambda}{2.6}$. This ratio is in agreement with those reported previously $\left(\frac{1}{1.5}<\frac{E_{\mathrm{a}}}{\lambda}<\frac{1}{3}\right)$ for outer-sphere electron transfer of $\left[\mathrm{Fe}(\mathrm{CN})_{6}\right]^{3-} /\left[\mathrm{Fe}(\mathrm{CN})_{6}\right]^{4-}$ redox on a $\mathrm{Au}$ electrode. ${ }^{30}$ Both temperature-independent reorganization energy and the proportionality between the free energy of activation and the reorganization energy suggest that the HER/HOR kinetics can be described by the MHC formalism.

We further calculated the static dielectric constant at the electrified interface using the Born model $\lambda=\frac{e^{2}}{8 \pi \varepsilon_{0} k_{\mathrm{B}} T}\left(\frac{1}{a_{0}}-\frac{1}{2 d}\right)\left(\frac{1}{\varepsilon_{\mathrm{op}}}-\frac{1}{\varepsilon_{\mathrm{s}}}\right), 38,40$ where $\varepsilon_{0}$ is the permittivity of free space, $a_{0}$ is the effective radius of the reactant, $d$ is the distance from the redox center to the surface of the electrode, $\varepsilon_{\text {op }}$ is the optical dielectric constant, and $\varepsilon_{\mathrm{s}}$ is the static dielectric constant of the electrolyte near the electrified interface. Note that the Born model of reorganization energy is a simple dielectric continuum model, which does not allow to identify which elementary reaction is the RDS during HER/ HOR. For Volmer step being the RDS, using the $\mathrm{O}-\mathrm{H}$ bond length of water molecule $(1 \AA)^{60}$ as the radius of redox species for $a_{0}$, the distance $d$ between redox (interfacial water molecules) and the electrode being the same as $a_{0}$, the optical dielectric constant of water $1.8,^{61,62}$ the cation-dependent 

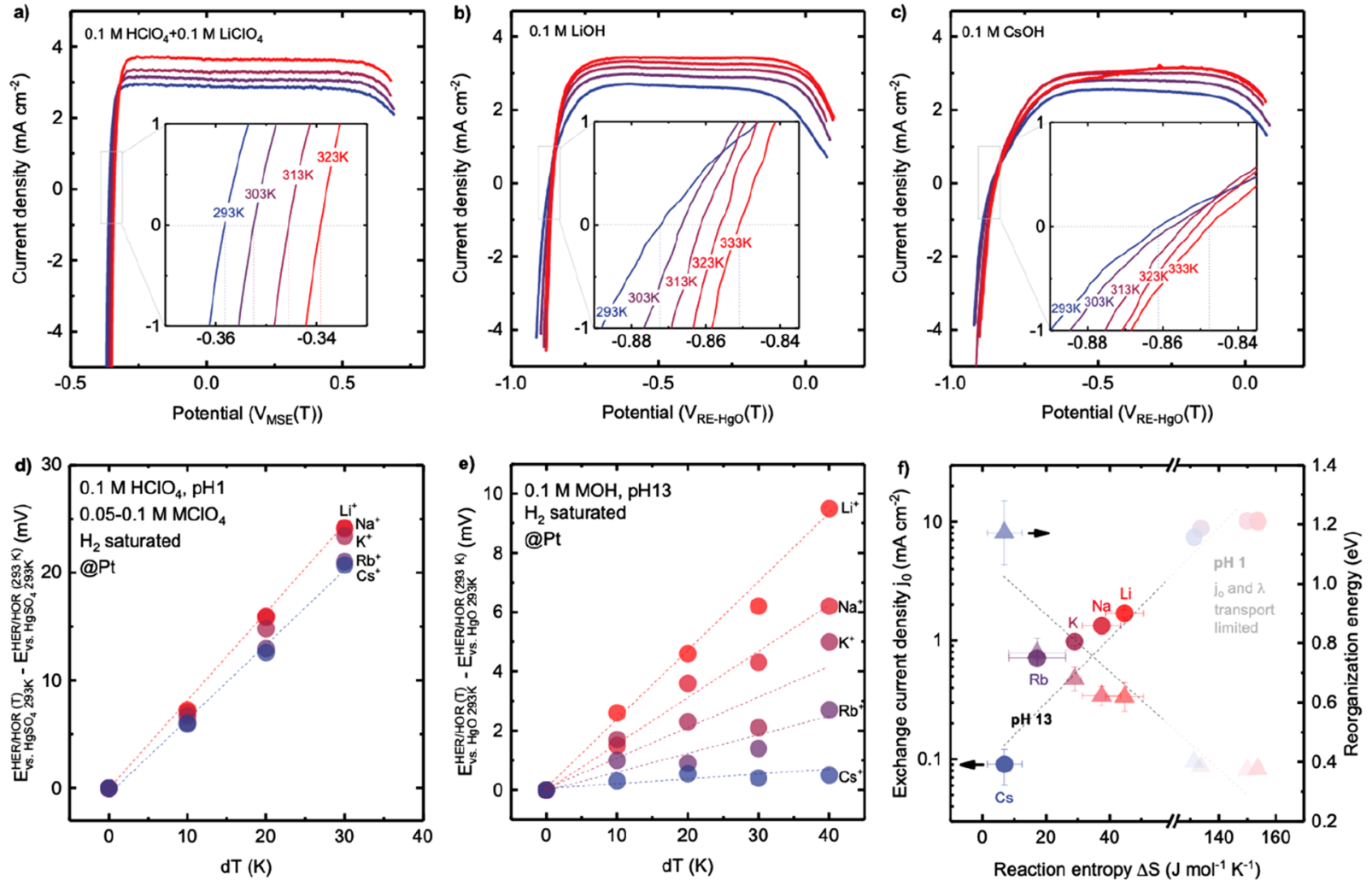

Figure 5. Cation- and pH-dependent reaction entropy change of HER/HOR on Pt RDE, determined by $\Delta S=n F\left[\frac{\mathrm{d} E_{\text {meas }}(T)}{\mathrm{d} T}+\frac{\mathrm{d} E_{R E}(T)}{\mathrm{d} T}\right](\operatorname{Appendix}$ S2). Temperature-dependent CV of HER/HOR measured on $\mathrm{Pt}$ at $\mathrm{pH} 1$ in $\mathrm{H}_{2}$-saturated $0.1 \mathrm{M} \mathrm{HClO}_{4}$ electrolyte (a) with $0.1 \mathrm{M} \mathrm{LiClO}_{4}$. Temperature-dependent CV of HER/HOR measured on $\mathrm{Pt}$ at $\mathrm{pH} 13$ of $\mathrm{H}_{2}$-saturated (b) $0.1 \mathrm{M} \mathrm{LiOH}$ and (c) $0.1 \mathrm{M}$ CsOH. Insets show the zoom-in of zero overpotential region. Temperature-dependent $\mathrm{HER} / \mathrm{HOR}$ potential vs the potential of reference electrode $\left(\mathrm{Hg} / \mathrm{HgSO} \mathrm{for}_{\mathrm{pH}} 1\right.$ and $\mathrm{Hg} / \mathrm{HgO}$ for $\mathrm{pH} 13$ ) at $293 \mathrm{~K}(\mathrm{~d})$ at $\mathrm{pH} 1$ and (e) at $\mathrm{pH}$ 13. (f) Cation dependence of the exchange current density $j_{0}$ and reorganization energy, as a function of reaction entropy, $\Delta S$, of HER/HOR at $\mathrm{pH} 1$ and $\mathrm{pH} 13$. Note that the kinetics $\left(j_{0}\right.$ and $\left.\lambda\right)$ of HER/HOR on Pt RDE at $\mathrm{pH}$ 1 was limited by mass transport (Figure S4) and cannot be separated from diffusion current density, thus the exchange current density at $\mathrm{pH} 1$ shown in Figure S5c does not reflect the pure HER/HOR kinetics at $\mathrm{pH}$ 1. The thermodynamic HER/HOR entropy changes were found to increase in the sequence of $\mathrm{Cs}^{+}<\mathrm{Rb}^{+}<\mathrm{K}^{+}<\mathrm{Na}^{+}<\mathrm{Li}^{+}$, where adsorbed $\mathrm{Cs}^{+}$and $\mathrm{Rb}^{+}$could expel interfacial water molecules and weaken the hydrogen-bonding network of surrounding water molecules at OHL, which leads to an increase in molar entropy of interfacial water molecules $S_{\mathrm{H}_{2} \mathrm{O}(\mathrm{l})}$ and interfacial hydronium $S_{\mathrm{H}_{3} \mathrm{O}^{+}(\mathrm{aq})}$, and a corresponding decrease in HER/HOR reaction entropy, $\Delta S=S_{\mathrm{H}_{2}(\mathrm{~g})}-2 \times S_{\mathrm{H}_{3} \mathrm{O}^{+}(\text {aq })}$ in acid $\left(2 \mathrm{H}_{(\mathrm{aq})}^{+}\right.$ $\left.+2 e^{-} \leftrightarrow \mathrm{H}_{2(\mathrm{~g})}\right)$ or $\Delta S=S_{\mathrm{H}_{2}(\mathrm{~g})}+2 \times S_{\left.\mathrm{OH}^{-}(\mathrm{aq})\right)}-2 \times S_{\mathrm{H}_{2} \mathrm{O}(\mathrm{l})}$ in alkaline electrolytes $\left(2 \mathrm{H}_{2} \mathrm{O}_{(\mathrm{l})}+2 e^{-} \leftrightarrow \mathrm{H}_{2(\mathrm{~g})}+2 \mathrm{OH}_{(\mathrm{aq})}^{-}\right)$. Error bars were obtained from the standard deviation of $2-3$ independent measurements. Full data points are available in Figure S10.

reorganization energy in Figure $4 \mathrm{~b}$ gave rise to cationdependent static dielectric constants at the electrified interface in the order of $\mathrm{Li}^{+}(2.6) \sim \mathrm{Na}^{+}(2.6)<\mathrm{K}^{+}(2.7)<\mathrm{Rb}^{+}(2.9)<$ $\mathrm{Cs}^{+}$(4.3) (Figure 4c). Assuming that $\mathrm{Pt}-\mathrm{H}_{\mathrm{ad}}$ bond length is not affected by the cation due to weak interaction between $\mathrm{H}_{\mathrm{ad}}$ and the cation (relative to water-cation interaction), the cation-dependent trend in the interfacial dielectric constant can also be found for the Heyrovsky being the RDS. Therefore, both Volmer and Heyrovsky pathways suggest a cationdependent interfacial static dielectric constant on the $\mathrm{Pt}$ surface at HER/HOR relevant potential region. These estimated static dielectric constants at the electrified interface are significantly lower than that of bulk water $(78.2)^{63}$ and $1 \mathrm{M}$ solutions of chloride salts of $\mathrm{Li}^{+}, \mathrm{Na}^{+}, \mathrm{K}^{+}, \mathrm{Rb}^{+}$, and $\mathrm{Cs}^{+}$ $(\sim 70),{ }^{63,64}$ which could originate from different cation/water molecule distributions at the electrified interface from MD simulations in Figure 1. The difference in the interfacial hydrogen-bonding structure induced by different cations has been revealed by in situ surface-enhanced infrared absorption spectroscopy in our previous work ${ }^{30}$ and in this work. These results are in agreement with previous $\mathrm{MD}$ simulation, showing that the static dielectric constant of water molecules can be significantly reduced to 2.1 at a planar hydrophobic interface from 80 in bulk. ${ }^{62}$ Further support comes from much reduced static dielectric constants of water confined at planar surfaces $(2-5),{ }^{62,65}$ spherical cavities $(40-60),{ }^{66}$ and spherical curvatures $(3-9)^{67}$ due to different interfacial water structures from bulk and cation concentrations at the electrified interface that can be greatly different from bulk. ${ }^{68,69}$

\section{pH- and Cation-Dependent Entropy Changes of HER/HOR}

We examined the $\mathrm{pH}$ and cation dependence of the HER/ HOR reaction entropy change $\Delta S$ from temperature-dependent potential measurements of HER/HOR, as shown in Figure $5 a-c$. Greater HER/HOR reaction entropy changes were found in acid (Figure 5a,d) than base (Figure 5b,c,e), regardless of the cations present, which suggests higher disorder in acid, in agreement with previous work by Ledezma-Yanez et al. ${ }^{12}$ The reaction entropy (131-154 J $\mathrm{mol}^{-1} \mathrm{~K}^{-1}$ for $\mathrm{pH} 1$ in $0.1 \mathrm{M} \mathrm{HClO}_{4}$ and $0.1 \mathrm{M}$ perchlorate of $\mathrm{Li}^{+} / \mathrm{Na}^{+}$or $0.08 \mathrm{M}$ perchlorate of $\mathrm{K}^{+} / \mathrm{Cs}^{+}$or $0.05 \mathrm{M}$ perchlorate of $\mathrm{Rb}^{+}$) is approximately 1 order magnitude higher 

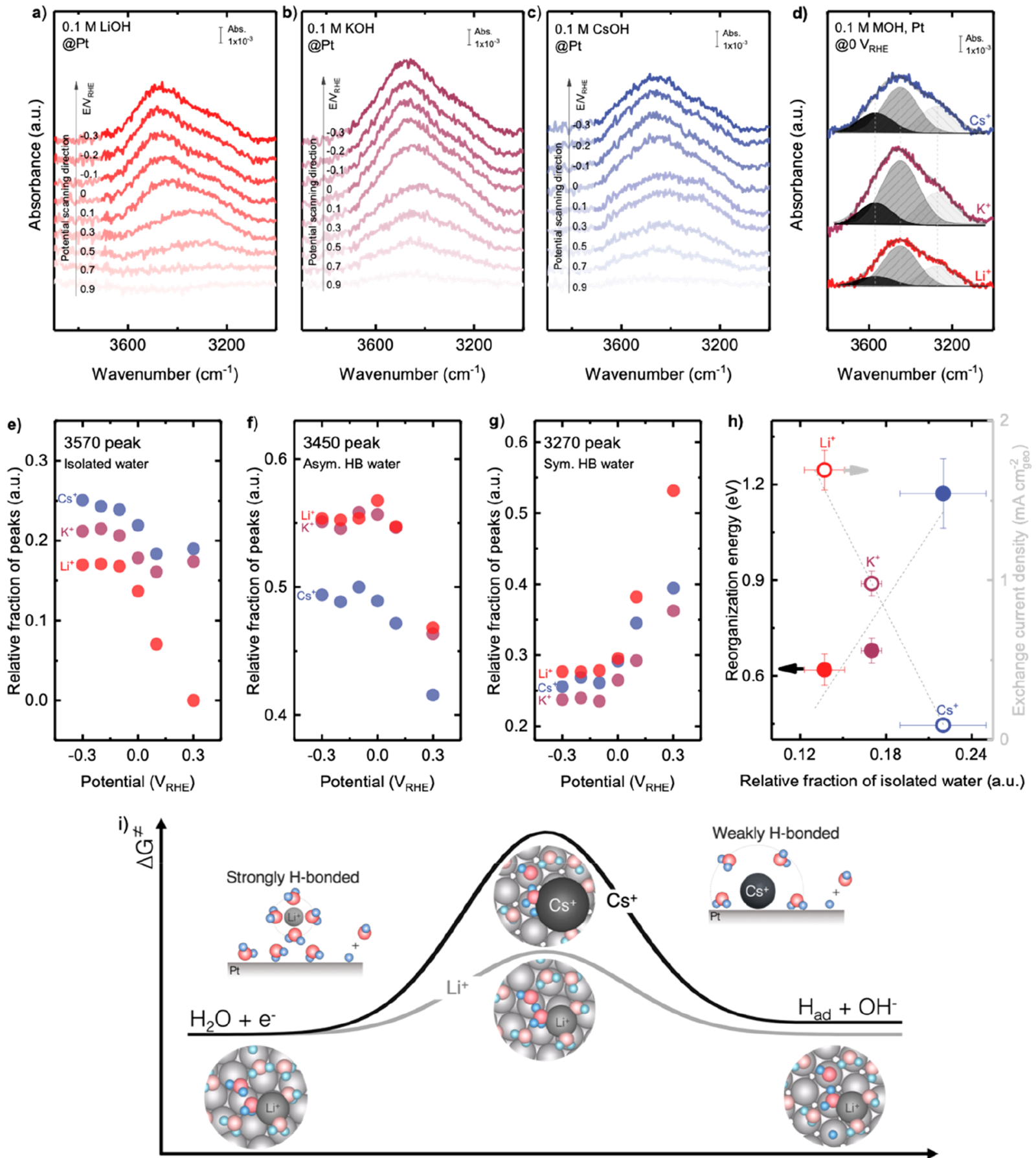

Figure 6. Altering interfacial structure at the Pt surface in aqueous electrolytes through noncovalent interactions associated with the hydrated cations, water molecules, and negatively charged Pt surface. The potential-dependent OH stretching features of in situ SEIRAS spectra of HER/ HOR measured from $0.9 \mathrm{~V}_{\mathrm{RHE}}$ to $-0.3 \mathrm{~V}_{\mathrm{RHE}}$ in a $\mathrm{H}_{2}$-saturated aqueous solution of $0.1 \mathrm{M}$ of (a) $\mathrm{LiOH}$, (b) $\mathrm{KOH}$, and (c) CsOH, where the reference spectrum was taken at $1.1 \mathrm{~V}_{\mathrm{RHE}}$. Full spectra before and after subtracting by reference spectrum (at $1.1 \mathrm{~V}_{\mathrm{RHE}}$ ) are available in Figure $\mathrm{S} 11$. (d) Deconvolution of the $\mathrm{OH}$ stretching peak at $0 \mathrm{~V}_{\mathrm{RHE}}$ into three components: $3570 \mathrm{~cm}^{-1}$ (weakly $\mathrm{H}$-bonded/isolated water), $3450 \mathrm{~cm}{ }^{-1}$ (asymmetric H-bonded water), and $3270 \mathrm{~cm}^{-1}$ (symmetric H-bonded water). The potential dependence of the relative fractions of (e) isolated water, (f) asymmetric H-bonded water, and (g) symmetric H-bonded water. (h) Reorganization energy and exchange current density of HER/ HOR measured on Pt RDE in $0.1 \mathrm{M}$ hydroxide of $\mathrm{Li}^{+}, \mathrm{K}^{+}$, and $\mathrm{Cs}^{+}$as a function of the relative fraction of isolated water. Error bars were obtained from the standard deviation of 2 independent measurements. (i) Scheme summarizing the proposed mechanisms of cation dependent kinetics of $\mathrm{HER} / \mathrm{HOR}$, where $\mathrm{Li}^{+}$ions retain their solvation shell intact and promote strongly hydrogen-bonded interfacial water layer, enhance protoncoupled electron transfer rate of the Volmer or Heyrovsky step by facilitating interfacial water molecule reorganization. Cs ${ }^{+}$ions partially desolvate and attach to the negatively charged Pt surface, promoting weakly $\mathrm{H}$-bonded interfacial water molecules, leading to an increase of the barrier of proton transfer during the Volmer or Heyrovsky step in HER/HOR on the Pt surface.

than that at $\mathrm{pH} 13$, with $0.1 \mathrm{M}$ hydroxide of $\mathrm{Li}^{+}, \mathrm{Na}^{+}, \mathrm{K}^{+}, \mathrm{Rb}^{+}$, and $\mathrm{Cs}^{+}\left(7-45 \mathrm{~J} \mathrm{~mol}^{-1} \mathrm{~K}^{-1}\right)$, as shown in Figure 5f. Moreover, while the HER/HOR entropy was found to be weakly cationdependent in acid (Figure 5f), cation dependence was 
significant in base, increasing in the sequence of $\mathrm{Cs}^{+}<\mathrm{Rb}^{+}<$ $\mathrm{K}^{+}<\mathrm{Na}^{+}<\mathrm{Li}^{+}$, as shown in Figure 5f. The trend can be attributed to the fact that the adsorption of cations in the decreasing order of $\mathrm{Cs}^{+}>\mathrm{Rb}^{+}>\mathrm{K}^{+}>\mathrm{Na}^{+}>\mathrm{Li}^{+}$at the electrified interface (Figure 1) could alter the hydrogenbonded water structure and solvation environment configurations at the interface. This hypothesis is supported by cation-dependent static dielectric constants extracted by the Born analysis of measured reaction entropy.

We further extracted the interfacial static dielectric constant of water using the Born model of reaction entropy $\Delta S=\frac{e^{2} N_{\mathrm{A}}}{8 \pi \varepsilon_{0} \varepsilon_{\mathrm{s}} T}\left(\frac{\mathrm{d} \ln \varepsilon_{\mathrm{s}}}{d T}\right)\left(\frac{Z_{\mathrm{ox}}^{2}}{r_{\mathrm{ox}}}-\frac{Z_{\mathrm{red}}^{2}}{r_{\mathrm{red}}}\right), 37,70$ where $T$ is temperature, $e$ is elementary charge, and $N_{\mathrm{A}}$ is the Avogadro constant. $\varepsilon_{0}$ is permittivity of free space; $\varepsilon_{\mathrm{s}}$ is static dielectric constant of solvent; $Z$ and $r$ are the charge and ionic radii of redox species, and compared to that extracted from Born model of reorganization energy (Figure 4b). Assuming the overall $\mathrm{HER} / \mathrm{HOR}$ reaction in alkaline electrolyte $2 \mathrm{H}_{2} \mathrm{O}+2 e^{-} \leftrightarrow$ $\mathrm{H}_{2}+2 \mathrm{OH}^{-}$, where the effective radius and charge of $\mathrm{H}$ atom in a $\mathrm{H}_{2} \mathrm{O}$ molecule are $r_{\mathrm{H}_{2} \mathrm{O}}=1.4 \AA$ and $Z_{\mathrm{H}_{2} \mathrm{O}}=+1, r_{\mathrm{H}_{2}}=1 \AA$, and $Z_{\mathrm{H}_{2}}=0$ for $\mathrm{H}$ atoms in $\mathrm{H}_{2}$ molecule, whereas $Z_{\mathrm{OH}^{-}}=+1$ for $\mathrm{H}$ atom in $\mathrm{OH}^{-}$anion. By fitting experimental data to Born model of reaction entropy with interfacial static dielectric constant obtained from reorganization energy (Figure 4c) and considering that the temperature dependence term, $\left(\frac{\mathrm{d} \ln \varepsilon_{\mathrm{s}}}{\mathrm{d} T}\right) \approx-1.42,{ }^{71}$ being the same as pure water for approximation (identical for all cation), the effective radii of $\mathrm{OH}^{-}, r_{\mathrm{OH}^{-}}$, was found to decrease in the order of $\mathrm{Li}^{+}(2.4)<$ $\mathrm{Na}^{+}(2.1)<\mathrm{K}^{+}(1.9)<\mathrm{Rb}^{+}(1.7)<\mathrm{Cs}^{+}(1.6)$, as shown in Figure $4 \mathrm{c}$. The cation-dependent trend in the effective radii of $\mathrm{OH}^{-}$is supported by the short-range effect of cations on the water structure in their solvation shell, where structurebreaking cations (e.g., $\mathrm{Cs}^{+}$) could decrease the effective radii of $\mathrm{OH}^{-}$by weakening the solvation structure of $\mathrm{OH}^{-}$, whereas structure-making cations (e.g., $\mathrm{Li}^{+}$) maintain their hydration shell and do not impact on the solvation structure of $\mathrm{OH}^{-}$. Using Davies equation, ${ }^{72}$ the activity coefficient of $\mathrm{OH}^{-}\left(\gamma_{\mathrm{OH}^{-}}\right)$ at the $\mathrm{Pt}$ interface was found to increase with cation radii from 0.21 for $\mathrm{Li}^{+}$and 0.48 for $\mathrm{Cs}^{+}$(Appendix S4), where the cationdependent trend is consistent with that reported by Harned and Swindells. ${ }^{73}$

We further estimated the Gibbs free energy of the reaction $\Delta G\left(\Delta G=\Delta G_{\mathrm{OH}^{-}}-\Delta G_{\mathrm{H}_{2} \mathrm{O}}\right)$, where the change of the Gibbs free energy, $\Delta G$, of $\mathrm{OH}^{-}$for $\mathrm{Li}^{+}$and $\mathrm{Cs}^{+}$, which should change by a factor of $-2.303 \cdot R \cdot T \cdot \log \left(\gamma_{\mathrm{OH}^{-}}\right)$according to Nernst equation. The values of $2.303 \cdot R \cdot T \cdot \log \left(\gamma_{\mathrm{OH}^{-}}\right)$can be estimated to be $-0.038 \mathrm{eV}$ for $\mathrm{Li}^{+}$and $-0.018 \mathrm{eV}$ for $\mathrm{Cs}^{+}$. Between the two extreme cations $\left(\mathrm{Li}^{+}\right.$and $\left.\mathrm{Cs}^{+}\right)$, the Gibbs free energy of the reaction $\Delta G$ varies by $0.02 \mathrm{eV}$, whereas the free energy of activation $\Delta G^{\ddagger}$ increases $0.23 \mathrm{eV}$ (from $0.23 \mathrm{eV}$ for $\mathrm{Li}^{+}$to 0.46 $\mathrm{eV}$ for $\mathrm{Cs}^{+}$, Figure $4 \mathrm{~b}$ ). The comparison of the Gibbs free energy of the reaction $\Delta G$ and the free energy of activation $\Delta G^{\ddagger}$ shows that the barrier of kinetics can be 1 order of magnitude larger than the thermodynamic driving force, the Gibbs free energy of the reaction $\Delta G$. The proportionality between the Gibbs free energy of the reaction $\Delta G$ and the free energy of activation $\Delta G^{\ddagger}$ indicates that the linear free energy relationship holds and could explain the cation-dependent HER/HOR kinetics at $\mathrm{pH} 13$ in this work.
We further showed that enthalpic contribution to the free energy of HER/HOR was small. For example, the entropic term of HER/HOR, $T \Delta S$, differed $0.11 \mathrm{eV}$ from $\mathrm{Li}^{+}$to $\mathrm{Cs}^{+}$ (with $\Delta S$ varies from 7 to $45 \mathrm{~K} \mathrm{~mol}^{-1} \mathrm{~K}^{-1}$ from $\mathrm{Cs}^{+}$to $\mathrm{Li}^{+}$), whereas the reaction enthalpy (peak potential of $\mathrm{H} / \mathrm{OH}$ exchange peaks) was almost cation-independent (Figure S15). This observation suggests that the entropic term is much more important in the free energy of the reaction than the enthalpic term in our case. Thus, the linear relationship between reaction entropy $\Delta S$ and activation entropy $\Delta S^{*}$ can be expected as enthalpic terms are small. Therefore, we try to examine the correlation between reaction entropy change $\Delta S$ (thermodynamic quantity) and kinetic quantities (e.g., exchange current density and reorganization energy) and understand the physical origin of such a correlation, as the activation entropy $\Delta S^{*}$ could not be quantified from experimental approaches or from reorganization energy in the MHC formalism. However, the reaction entropy change $\Delta S$ can be obtained from temperature-dependent potential (Appendix S2). From our previous work, ${ }^{30}$ we demonstrated that the kinetics (exchange current density and reorganization energy) correlated strongly with the reaction entropy of $\left[\mathrm{Fe}(\mathrm{CN})_{6}\right]^{3-/ 4-}$ redox (an outersphere electron-transfer reaction), which was associated with the disordering/ordering of the solvation environment of the redox centers at electrode surface. In this work, the HER/HOR reaction entropy is a measure of the disordering of solvation structures at electrified interface and can be used to extract the interfacial dielectric constant, suggesting that cation-dependent reaction entropy is associated with cation-dependent interfacial solvation structure. Furthermore, our studies demonstrated that the exchange current density (kinetics) increased with increasing reaction entropy change $\Delta S$ for proton-coupled electron transfer (HER/HOR in this work, as shown in Figure 5f) and for outer-sphere electron transfer $\left(\left[\mathrm{Fe}(\mathrm{CN})_{6}\right]^{3-/ 4-}\right.$ redox in our previous work ${ }^{30}$ ).

\section{Cation-Dependent Water Structures at the Electrified Interface}

We employed in situ SEIRAS to probe interfacial water structures on $\mathrm{Pt}$ during $\mathrm{HER} / \mathrm{HOR}$ as a function of voltage from 1.1 to $-0.3 \mathrm{~V}_{\mathrm{RHE}}$ in the electrolyte containing $0.1 \mathrm{M}$ hydroxide of $\mathrm{Li}^{+}, \mathrm{K}^{+}$, and $\mathrm{Cs}^{+}$, where $\mathrm{OH}$ stretching $(\sim 3600-$ $\left.3200 \mathrm{~cm}^{-1}\right)$ and $\mathrm{HOH}$ bending $\left(\sim 1700-1600 \mathrm{~cm}^{-1}\right)$ were probed (Figures 6 and S12). Figure $6 a-c$ shows the $\mathrm{OH}$ stretching features of in situ SEIRAS spectra measured in the presence of $\mathrm{Li}^{+}, \mathrm{K}^{+}$, and $\mathrm{Cs}^{+}$, respectively. It should be noted that the PZC of $\mathrm{Pt}(111)$ at $\mathrm{pH} 13$ was at the potential of 1.1 $\mathrm{V}_{\mathrm{RHE}}$, where the reference spectrum of SEIRAS was measured. Note that the PZC of Pt does not change drastically with surface facets (Appendix S3). The Pt electrode surface was negatively charged at potentials below PZC, and the surface charge increased with decreasing potentials, which could result in the increase of the intensity of $\mathrm{OH}$ stretching peak when the potential decreased from 0.9 to $-0.3 \mathrm{~V}_{\mathrm{RHE}}$. The $\mathrm{OH}$ stretching peaks were further deconvoluted into three components: weakly $\mathrm{H}$-bonded water at $3570 \mathrm{~cm}^{-1,36,74}$ asymmetric $\mathrm{H}$ bonded water molecules at $3450 \mathrm{~cm}^{-1}$ (water-cation interaction, i.e., water molecules solvating cations), ${ }^{36,74}$ and symmetric $\mathrm{H}$-bonded water molecules at $3270 \mathrm{~cm}^{-1}$ (waterwater interaction, i.e., ice-like water or bulk water), ${ }^{36,74}$ as shown in Figure $6 \mathrm{~d}$ for $0 \mathrm{~V}_{\mathrm{RHE}}$ and Figure $\mathrm{S} 13$ for other potentials. The potential-dependent relative fractions of deconvoluted peaks for weakly H-bonded water, asymmetric, 
and symmetric H-bonded water molecules are shown in Figure $6 \mathrm{e}-\mathrm{g}$. The relative fraction of weakly $\mathrm{H}$-bonded water at the electrified interface was found to increase with decreasing potential (Figure 6e), which was attributed to the increase in $\mathrm{Pt}$-water dipole interaction due to higher surface charge. The relative fraction of asymmetric $\mathrm{H}$-bonded water molecules was shown to increase with decreasing potential (Figure 6f), which can be attributed to the increase of hydrated cations at the electrified interface when $\mathrm{Pt}$ surface charge was more negative at lower potential. The relative fraction of symmetric $\mathrm{H}$ bonded water molecules decreased with decreasing potential (Figure 6g), which can be due to the replacement of symmetric $\mathrm{H}$-bonded water by hydrated cations. At a given potential, such as $0 \mathrm{~V}_{\mathrm{RHE}}$, the relative peak fraction of weakly $\mathrm{H}$-bonded water at the interface was shown to increase in the order from $\mathrm{Li}^{+}$to $\mathrm{K}^{+}$to $\mathrm{Cs}^{+}$(Figure 6e), whereas that of strongly H-bonded (asymmetric and symmetric) water decreased (Figure S14). The observation agrees with more cations and less water molecules at the electrified interface for $\mathrm{Cs}^{+}$compared to $\mathrm{Li}^{+}$, as shown schematically in Figure 1a,b, which is consistent with $\mathrm{HOH}$ bending features. The $\mathrm{HOH}$ bending vibration peak (Figure S12) also showed similar trends for the hydrogenbonding network of interfacial water molecules, where the peaks at $\sim 1605$ and $\sim 1626 \mathrm{~cm}^{-1}$ correspond to weakly $\mathrm{H}$ bonded and strongly $\mathrm{H}$-bonded water molecules, respectively. ${ }^{74,75}$ In the presence of $\mathrm{Li}^{+}$, the Pt surface was mainly covered by strongly (symmetric and asymmetric) H-bonded water, which increased its intensity with decreasing potential (Figure S12a). In the case of $\mathrm{Cs}^{+}$, the intensity of the peak at $\sim 1610 \mathrm{~cm}^{-1}$ (weakly $\mathrm{H}$-bonded water) was more significant (Figure S12c) compared to that of $\mathrm{Li}^{+}$, resulting in an increased fraction of weakly $\mathrm{H}$-bonded water. Note that although a spectroscopic technique such as in situ SEIRAS could probe the interactions between cations and interfacial water molecules, further techniques are needed to quantify the adsorption energy and identify whether this adsorption involves electron transfer to the cation and how it depends on the nature of the cations.

\section{Relating HER/HOR Kinetics to Surface Chemistry and} Solvation Environments at the Electrified Interface

We further examine and correlate the peak potential determined from $\mathrm{CVs}$ (the peaks of $\mathrm{H} / \mathrm{OH}$ exchange on $\mathrm{Pt}(110)$ and $\mathrm{Pt}(100)$ facets $)^{28,76,77}$ with the HER/HOR kinetics, as it has been suggested to govern the HER/HOR activity in a wide range of electrolyte with $\mathrm{pH}$ from 0 to 13 on platinum group metals, e.g., $\mathrm{Pt}{ }^{8,9,14} \mathrm{Ir}^{9,14} \mathrm{Pd}^{8,9,14}$ and $\mathrm{Rh}^{9}$ The peak potentials were extracted from CV measured in Arsaturated electrolytes on polycrystalline $\mathrm{Pt}$ in a base (Figure $\mathrm{S} 15 \mathrm{a}$ ) and in an acid (Figure S15b) following previous work, ${ }^{8,9}$ where the peaks at $\sim 0.25$ and $\sim 0.32 \mathrm{~V}_{\mathrm{RHE}}$ correspond to the potentials of the $\mathrm{H}$ desorption peak at $\mathrm{Pt}(110)$ and $\mathrm{Pt}(100)$ facets, respectively. ${ }^{8,9}$ Increasingly, peak potential from 0.12 to $0.27 \mathrm{eV}$ for the $\mathrm{Pt}(110)$ facet and from 0.25 to $0.39 \mathrm{eV}$ for the $\mathrm{Pt}(100)$ facet was observed for increasing $\mathrm{pH}$ from 1 to 14 (Figure S15c,d), in agreement with previous work. ${ }^{8,9}$ Note that the peaks of $\mathrm{Pt}(110)$ and $\mathrm{Pt}(100)$ of $\mathrm{CVs}$ measured on polycrystalline $\mathrm{Pt}$ result from a competitive $\mathrm{H} / \mathrm{OH}$ exchange, therefore convoluting $\mathrm{HBE}$ and $\mathrm{OH}$ binding energy (OHBE). ${ }^{28,76,77}$ Interestingly, the experimental values of peak potential determined from $\mathrm{CV}$ at a given $\mathrm{pH}$ were almost independent of cations (Figure S15), whereas the exchange current density normalized by the geometric surface was changed by $1-2$ orders of magnitude from $\mathrm{Cs}^{+}$to $\mathrm{Li}^{+}$(Figure $S 15 c, d)$. Therefore, our result indicates that the experimentally measured peak potential from the CV cannot explain the cation-dependent HER/HOR kinetics, which could arise from the coadsorption of $\mathrm{H}_{\mathrm{ad}}, \mathrm{OH}_{\mathrm{ad}}$, and cations in low potential region $\left(0-0.4 \mathrm{~V}_{\mathrm{RHE}}\right){ }^{28}$ and consequently, the peak shifts from hydrogen underpotential deposition regions might not be appropriate to extract the binding energy of $\mathrm{H}_{\mathrm{ad}} \cdot{ }^{28}$

We further showed that the HER/HOR exchange current density normalized by geometric surface $j_{0}$ correlated strongly with reaction entropy change $\Delta S$, where the exchange current density increased with increasing reaction entropy (Figure 5f). In addition, smaller reorganization energy of $\mathrm{HER} / \mathrm{HOR}$ kinetics is associated with greater reaction entropy change (Figure S16a). Such correlation has also been observed for outer-sphere electron-transfer reaction in our previous work. ${ }^{30}$ These results suggest that having more disordered solvation environments at the electrolyte/electrode interface with greater solvating configurations can increase the exchange current density and reduce reorganization energy during electron transfer $^{30}$ or proton-coupled electron-transfer processes (Figure 5f and Figure S16).

Our in situ SEIRAS experiments further revealed that solvation environments at the electrified interface can be altered by spectator cations in the electrolyte, where structurebreaking cations (such as $\mathrm{Cs}^{+}$) could expel interfacial water molecules (Figure 1a) and reduce the interfacial H-bonding network and promote weakly $\mathrm{H}$-bonded water molecules at the electrified Pt surface (Figure 6e and Figure S14). A similar cation effect on interfacial water structures on the Au surface during outer-sphere electron transfer has been observed in our previous work. ${ }^{30}$ The weakly H-bonded interfacial environment was shown to enhance the reaction rate of outer-sphere electron-transfer processes. Unlikely, the weakly H-bonded interfacial solvation environment could increase the barrier of proton-coupled electron transfer from water in the Volmer step $\left(\mathrm{H}_{2} \mathrm{O}+e^{-}+* \leftrightarrow \mathrm{H}_{\mathrm{ad}}+\mathrm{OH}^{-}\right)$or Heyrovsky step $\left(\mathrm{H}_{\mathrm{ad}}+\mathrm{H}_{2} \mathrm{O}\right.$ $+e^{-} \leftrightarrow \mathrm{H}_{2}+\mathrm{OH}^{-}+*$ ) during HER/HOR (Figure 6h,i). In addition, as the HER/HOR potential on the RHE scale differs on the SHE scale for electrolytes of different $\mathrm{pH},{ }^{12,78}$ different water dipole orientation, ${ }^{6,12,74}$ solvation, and adsorption of cations at the electrified interface as a function of $\mathrm{pH}$ can influence the energetics of water adsorption/desorption at $\mathrm{Pt}$ (111) during HER/HOR. ${ }^{79}$ Specifically, larger alkali metal cations can adsorb more easily on the metal surface in alkaline electrolytes, due to stronger Coulombic interactions associated with hydrated cations and $\mathrm{Pt}$ surface induced by the higher surface charge at $\mathrm{pH} 13$ than at $\mathrm{pH} 1 .^{31,54}$ The negative charge of the Pt surface in base attracts cations and hydrogen dipole of interfacial water molecules, leading to an ordered interfacial structure at the electrified interface. In the acidic electrolytes, the $\mathrm{Pt}$ surface becomes less negatively charged, ${ }^{31,54}$ which interacts more weakly with both water and cations to induce a more disordered interfacial layer, rendering greater reaction entropy (Figure 5f). Going beyond the PZC-dependent interfacial water structure descriptor of HER/HOR kinetics, ${ }^{12}$ which does not explain the asymmetrical effect of the shift in PZC on HER and HOR activity, ${ }^{77}$ we propose that the difference in HER/HOR kinetics in acid and in base can be attributed to the adsorbed cations on Pt surfaces at the HER/ HOR potential region.

The proposed mechanism in this work (Figure 6i) is in agreement with previous work, ${ }^{12}$ suggesting $\mathrm{pH}$-dependent 
interfacial water structure as the HER kinetics descriptor, where faster kinetics in acid are associated with higher entropy with less ordered structure in acid and lower reorganization energy for interfacial water than those in the base. In addition, the trends in the HER/HOR kinetics and proposed explanation is consistent with recent computational findings ${ }^{29}$ on $\mathrm{pH}$-dependent proton transfer barriers for $\mathrm{HER} / \mathrm{HOR}$ kinetics, where greater $\mathrm{pH}$ is correlated with a larger entropic barrier of proton transfer across the outer Helmholtz layer and thus lowered HER/HOR kinetics. This work highlights promising opportunities to control the reaction rates by tuning the solvation environments at the electrified interface. Further experimental and computation fundamental studies are needed to understand how these solvation environments at the electrified interface can alter water adsorption and dissociation and proton transfer kinetics in details.

\section{CONCLUSIONS}

Classical MD simulation of electrolytes containing $1 \mathrm{M}$ cation of $\mathrm{Li}^{+}, \mathrm{Na}^{+}, \mathrm{K}^{+}, \mathrm{Rb}^{+}$, and $\mathrm{Cs}^{+}$at $\mathrm{pH} 1$ and $\mathrm{pH} 13$ at the $\mathrm{Pt}(111)$ interface has shown that the local solvation environment at the electrified interface is cation-dependent. Electrolytes containing larger (more structure-breaking) cations yield more surface-bound cations than those containing smaller (more structure-making) cations. These differences can result in a cation-dependent interfacial hydrogen-bonding network, which was probed by in situ SEIRAS measurements. The cationdependent interfacial water structure can further alter the effective dielectric and fluctuations that determine solvent reorganization energy. The contribution to the HER/HOR kinetics on the Pt RDE surface from the interfacial structure change induced by redox-inactive structure-making/breaking cations and $\mathrm{pH}$ of electrolytes was systematically probed. We show that the HER/HOR exchange current density $j_{0}$ decreases with increasing $\mathrm{pH}$ by 2 orders of magnitude, where the cation dependence becomes more pronounced in the order of $\mathrm{Li}^{+}, \mathrm{Na}^{+}, \mathrm{K}^{+}, \mathrm{Rb}^{+}$, and $\mathrm{Cs}^{+}$. We further show that the exchange current density of HER/HOR increases with increasing reaction entropy. Using the Born model of reorganization energy (extracted by MHC formalism) and reaction entropy (experimentally measured), the interfacial static dielectric constant has been estimated to be significantly lower than that in bulk electrolyte and increases in the order of $\mathrm{Li}^{+}<\mathrm{Na}^{+}<\mathrm{K}^{+}<\mathrm{Rb}^{+}<\mathrm{Cs}^{+}$on negatively charged Pt RDE. The findings of this study can have broader implications for the chemical physics of electrolytes on electron transfer and proton-coupled electron-transfer reactions at the electrified interface, which can be leveraged to tune the kinetic rates and selectivity of electrochemical reactions for achieving the decarbonization of sustainable fuels and chemical transformations.

\section{ASSOCIATED CONTENT}

\section{Supporting Information}

The Supporting Information is available free of charge at https://pubs.acs.org/doi/10.1021/jacsau.1c00281.

Cyclic voltammograms; Koutecky-Levich analysis; cation-dependent kinetics current density per ECSA and per geometric surface; Tafel slope; calculated Nernstian diffusion overpotential; temperature-dependent kinetics current density; in situ SEIRAS spectra; deconvolution of $\mathrm{OH}$ stretching peak; force field parameters of classical MD simulation (PDF)

\section{AUTHOR INFORMATION}

\section{Corresponding Authors}

Botao Huang - Electrochemical Energy Laboratory and Research Laboratory of Electronics, Massachusetts Institute of Technology, Cambridge, Massachusetts 02139, United States; 10 orcid.org/0000-0001-5634-5620; Email: huang73@mit.edu

Yang Shao-Horn - Electrochemical Energy Laboratory, Department of Mechanical Engineering, and Department of Material Science and Engineering, Massachusetts Institute of Technology, Cambridge, Massachusetts 02139, United States; (1) orcid.org/0000-0001-8714-2121;

Email: shaohorn@mit.edu

\section{Authors}

Reshma R. Rao - Electrochemical Energy Laboratory and Research Laboratory of Electronics, Massachusetts Institute of Technology, Cambridge, Massachusetts 02139, United States

Sifan You - International Center for Quantum Materials, School of Physics, Peking University, Beijing 100871, People's Republic of China

Kyaw Hpone Myint - Department of Chemistry, Massachusetts Institute of Technology, Cambridge, Massachusetts 02139, United States

Yizhi Song - International Center for Quantum Materials, School of Physics, Peking University, Beijing 100871, People's Republic of China

Yanming Wang - Research Laboratory of Electronics, Massachusetts Institute of Technology, Cambridge, Massachusetts 02139, United States; Present Address: University of Michigan-Shanghai Jiao Tong University Joint Institute, Shanghai Jiao Tong University, Shanghai, 200240, People's Republic of China;

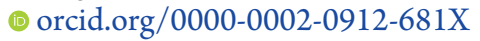

Wendu Ding - Department of Chemistry, Massachusetts Institute of Technology, Cambridge, Massachusetts 02139, United States; 이이.org/0000-0002-9643-6161

Livia Giordano - Electrochemical Energy Laboratory and Research Laboratory of Electronics, Massachusetts Institute of Technology, Cambridge, Massachusetts 02139, United States; orcid.org/0000-0002-6879-9424

Yirui Zhang - Electrochemical Energy Laboratory and Department of Mechanical Engineering, Massachusetts Institute of Technology, Cambridge, Massachusetts 02139, United States; 10 orcid.org/0000-0001-7604-8623

Tao Wang - Electrochemical Energy Laboratory and Research Laboratory of Electronics, Massachusetts Institute of Technology, Cambridge, Massachusetts 02139, United States

Sokseiha Muy - Electrochemical Energy Laboratory and Research Laboratory of Electronics, Massachusetts Institute of Technology, Cambridge, Massachusetts 02139, United States

Yu Katayama - Electrochemical Energy Laboratory, Massachusetts Institute of Technology, Cambridge, Massachusetts 02139, United States; Department of Applied Chemistry, Graduate School of Sciences and Technology for Innovation, Yamaguchi University, Ube 755-8611, Japan; (1) orcid.org/0000-0002-7842-2938

Jeffrey C. Grossman - Department of Material Science and Engineering, Massachusetts Institute of Technology, 
Cambridge, Massachusetts 02139, United States; (1) orcid.org/0000-0003-1281-2359

Adam P. Willard - Department of Chemistry, Massachusetts Institute of Technology, Cambridge, Massachusetts 02139, United States; 10 orcid.org/0000-0002-0934-4737

Kang Xu - Battery Science Branch, Sensor and Electron Devices Directorate, U.S. Army Research Laboratory, Adelphi, Maryland 20783-1197, United States;

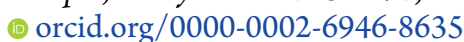

Ying Jiang - International Center for Quantum Materials, School of Physics, Peking University, Beijing 100871, People's Republic of China

Complete contact information is available at: https://pubs.acs.org/10.1021/jacsau.1c00281

\section{Author Contributions}

B.H., K.X., and Y.S.-H. designed the experiments. B.H. carried out electrochemical measurements and in situ SEIRAS experiments and performed analysis. K.H.M. and Y.W. performed classical MD simulations. B.H. prepared the initial manuscript. All authors contributed to the discussion and revision of the manuscript.

Notes

The authors declare no competing financial interest.

\section{ACKNOWLEDGMENTS}

This work was supported in part by Broad Agency Announcement (BAA) for Basic and Applied Scientific Research funded by the U.S. Army Research Laboratory (ARL), the U.S. Department of Defense (DoD), under Award Number W911NF1920065, by a grant from MISTI-China (Project No. 2244703). K.X. also wants to thank the financial support from JCESR, an Energy Hub sponsored by the U.S. Department of Energy (DoE) Office of Basic Energy Science. B.H. acknowledges Dr. B. Cai and Dr. J.C. Eom for discussions and comments, J. Sun for technical support, and Dr. Y.G. Zhu for ICP measurement. Y.K. received funding from the JSPS KAKENHI under Grant No. 19K15360 and JSPS Open Partnership Joint Research Projects (JPJSBP 120209925).

\section{REFERENCES}

(1) Seh, Z. W.; Kibsgaard, J.; Dickens, C. F.; Chorkendorff, I.; Nørskov, J. K.; Jaramillo, T. F. Combining Theory and Experiment in Electrocatalysis: Insights into Materials Design. Science 2017, 355 (6321), No. eaad4998.

(2) Stamenkovic, V.; Mun, B. S.; Mayrhofer, K. J. J.; Ross, P. N.; Markovic, N. M.; Rossmeisl, J.; Greeley, J.; Nørskov, J. K. Changing the Activity of Electrocatalysts for Oxygen Reduction by Tuning the Surface Electronic Structure. Angew. Chem., Int. Ed. 2006, 45 (18), 2897-2901.

(3) Hwang, J.; Rao, R. R.; Giordano, L.; Katayama, Y.; Yu, Y.; ShaoHorn, Y. Perovskites in Catalysis and Electrocatalysis. Science 2017, 358 (6364), 751.

(4) Armand, M.; Tarascon, J.-M. Building Better Batteries. Nature 2008, 451, 652.

(5) Suntivich, J.; Gasteiger, H. A.; Yabuuchi, N.; Nakanishi, H.; Goodenough, J. B.; Shao-Horn, Y. Design Principles for OxygenReduction Activity on Perovskite Oxide Catalysts for Fuel Cells and Metal-Air Batteries. Nat. Chem. 2011, 3, 546.

(6) Strmcnik, D.; Lopes, P. P.; Genorio, B.; Stamenkovic, V. R.; Markovic, N. M. Design Principles for Hydrogen Evolution Reaction Catalyst Materials. Nano Energy 2016, 29, 29-36.
(7) Tymoczko, J.; Calle-Vallejo, F.; Schuhmann, W.; Bandarenka, A. S. Making the Hydrogen Evolution Reaction in Polymer Electrolyte Membrane Electrolysers Even Faster. Nat. Commun. 2016, 7, 10990.

(8) Sheng, W.; Zhuang, Z.; Gao, M.; Zheng, J.; Chen, J. G.; Yan, Y. Correlating Hydrogen Oxidation and Evolution Activity on Platinum at Different PH with Measured Hydrogen Binding Energy. Nat. Commun. 2015, 6, 5848.

(9) Zheng, J.; Sheng, W.; Zhuang, Z.; Xu, B.; Yan, Y. Universal Dependence of Hydrogen Oxidation and Evolution Reaction Activity of Platinum-Group Metals on PH and Hydrogen Binding Energy. Sci. Adv. 2016, 2 (3), No. e1501602.

(10) McCrum, I. T.; Koper, M. T. M. The Role of Adsorbed Hydroxide in Hydrogen Evolution Reaction Kinetics on Modified Platinum. Nature Energy 2020, 5 (11), 891-899.

(11) Strmcnik, D.; Kodama, K.; van der Vliet, D.; Greeley, J.; Stamenkovic, V. R.; Marković, N. M. The Role of Non-Covalent Interactions in Electrocatalytic Fuel-Cell Reactions on Platinum. Nat. Chem. 2009, 1 (6), 466-472.

(12) Ledezma-Yanez, I.; Wallace, W. D. Z.; Sebastián-Pascual, P.; Climent, V.; Feliu, J. M.; Koper, M. T. M. Interfacial Water Reorganization as a PH-Dependent Descriptor of the Hydrogen Evolution Rate on Platinum Electrodes. Nature Energy 2017, 2, 17031.

(13) Zhang, R.; Pearce, P. E.; Duan, Y.; Dubouis, N.; Marchandier, T.; Grimaud, A. Importance of Water Structure and CatalystElectrolyte Interface on the Design of Water Splitting Catalysts. Chem. Mater. 2019, 31, 8248-8259.

(14) Durst, J.; Siebel, A.; Simon, C.; Hasche, F.; Herranz, J.; Gasteiger, H. A. New Insights into the Electrochemical Hydrogen Oxidation and Evolution Reaction Mechanism. Energy Environ. Sci. 2014, 7 (7), 2255-2260.

(15) Durst, J.; Simon, C.; Siebel, A.; Rheinländer, P. J.; Schuler, T.; Hanzlik, M.; Herranz, J.; Hasché, F.; Gasteiger, H. A. (Invited) Hydrogen Oxidation and Evolution Reaction (HOR/HER) on $\mathrm{Pt}$ Electrodes in Acid vs. Alkaline Electrolytes: Mechanism, Activity and Particle Size Effects. ECS Trans. 2014, 64 (3), 1069-1080.

(16) Sheng, W.; Gasteiger, H. A.; Shao-Horn, Y. Hydrogen Oxidation and Evolution Reaction Kinetics on Platinum: Acid vs Alkaline Electrolytes. J. Electrochem. Soc. 2010, 157 (11), B1529B1536.

(17) Singh, M. R.; Kwon, Y.; Lum, Y.; Ager, J. W.; Bell, A. T. Hydrolysis of Electrolyte Cations Enhances the Electrochemical Reduction of $\mathrm{CO} 2$ over Ag and Cu. J. Am. Chem. Soc. 2016, 138 (39), 13006-13012.

(18) Pérez-Gallent, E.; Marcandalli, G.; Figueiredo, M. C.; CalleVallejo, F.; Koper, M. T. M. Structure- and Potential-Dependent Cation Effects on CO Reduction at Copper Single-Crystal Electrodes. J. Am. Chem. Soc. 2017, 139 (45), 16412-16419.

(19) Rheinländer, P. J.; Herranz, J.; Durst, J.; Gasteiger, H. A. Kinetics of the Hydrogen Oxidation/Evolution Reaction on Polycrystalline Platinum in Alkaline Electrolyte Reaction Order with Respect to Hydrogen Pressure. J. Electrochem. Soc. 2014, 161 (14), F1448-F1457.

(20) Intikhab, S.; Snyder, J. D.; Tang, M. H. Adsorbed Hydroxide Does Not Participate in the Volmer Step of Alkaline Hydrogen Electrocatalysis. ACS Catal. 2017, 7 (12), 8314-8319.

(21) Liu, L.; Liu, Y.; Liu, C. Enhancing the Understanding of Hydrogen Evolution and Oxidation Reactions on $\mathrm{Pt}(111)$ through $\mathrm{Ab}$ Initio Simulation of Electrode/Electrolyte Kinetics. J. Am. Chem. Soc. 2020, 142 (11), 4985-4989.

(22) Lamoureux, P. S.; Singh, A. R.; Chan, K. PH Effects on Hydrogen Evolution and Oxidation over $\operatorname{Pt}(111)$ : Insights from FirstPrinciples. ACS Catal. 2019, 9 (7), 6194-6201.

(23) Zheng, Y.; Jiao, Y.; Vasileff, A.; Qiao, S.-Z. The Hydrogen Evolution Reaction in Alkaline Solution: From Theory, Single Crystal Models, to Practical Electrocatalysts. Angew. Chem., Int. Ed. 2018, 57 (26), 7568-7579. 
(24) Dubouis, N.; Grimaud, A. The Hydrogen Evolution Reaction: From Material to Interfacial Descriptors. Chem. Sci. 2019, 10 (40), 9165-9181.

(25) Liu, E.; Li, J.; Jiao, L.; Doan, H. T. T.; Liu, Z.; Zhao, Z.; Huang, Y.; Abraham, K. M.; Mukerjee, S.; Jia, Q. Unifying the Hydrogen Evolution and Oxidation Reactions Kinetics in Base by Identifying the Catalytic Roles of Hydroxyl-Water-Cation Adducts. J. Am. Chem. Soc. 2019, 141 (7), 3232-3239.

(26) Xue, S.; Garlyyev, B.; Watzele, S.; Liang, Y.; Fichtner, J.; Pohl, M. D.; Bandarenka, A. S. Influence of Alkali Metal Cations on the Hydrogen Evolution Reaction Activity of Pt, Ir, Au, and Ag Electrodes in Alkaline Electrolytes. ChemElectroChem 2018, 5 (17), 2326-2329.

(27) Zheng, J.; Nash, J.; Xu, B.; Yan, Y. Perspective-Towards Establishing Apparent Hydrogen Binding Energy as the Descriptor for Hydrogen Oxidation/Evolution Reactions. J. Electrochem. Soc. 2018, 165 (2), H27-H29.

(28) Chen, X.; McCrum, I. T.; Schwarz, K. A.; Janik, M. J.; Koper, M. T. M. Co-Adsorption of Cations as the Cause of the Apparent PH Dependence of Hydrogen Adsorption on a Stepped Platinum SingleCrystal Electrode. Angew. Chem., Int. Ed. 2017, 56 (47), 1502515029.

(29) Rossmeisl, J.; Chan, K.; Skúlason, E.; Björketun, M. E.; Tripkovic, V. On the PH Dependence of Electrochemical Proton Transfer Barriers. Catal. Today 2016, 262, 36-40.

(30) Huang, B.; Myint, K. H.; Wang, Y.; Zhang, Y.; Rao, R. R.; Sun, J.; Muy, S.; Katayama, Y.; Corchado Garcia, J.; Fraggedakis, D.; Grossman, J. C.; Bazant, M. Z.; Xu, K.; Willard, A. P.; Shao-Horn, Y. Cation-Dependent Interfacial Structures and Kinetics for OuterSphere Electron-Transfer Reactions. J. Phys. Chem. C 2021, 125 (8), 4397-4411.

(31) Rizo, R.; Sitta, E.; Herrero, E.; Climent, V.; Feliu, J. M. Towards the Understanding of the Interfacial PH Scale at $\operatorname{Pt}(111)$ Electrodes. Electrochim. Acta 2015, 162, 138-145.

(32) Hockney, R. W.; Eastwood, J. W. Computer Simulation Using Particles, 1st ed.; Taylor \& Francis, Inc.: Philadelphia, 1988.

(33) Berendsen, H. J. C.; Grigera, J. R.; Straatsma, T. P. The Missing Term in Effective Pair Potentials. J. Phys. Chem. 1987, 91 (24), 62696271.

(34) Heinz, H.; Vaia, R. A.; Farmer, B. L.; Naik, R. R. Accurate Simulation of Surfaces and Interfaces of Face-Centered Cubic Metals Using 12-6 and 9-6 Lennard-Jones Potentials. J. Phys. Chem. C 2008, 112 (44), 17281-17290.

(35) Wang, Z.; Yang, Y.; Olmsted, D. L.; Asta, M.; Laird, B. B. Evaluation of the Constant Potential Method in Simulating Electric Double-Layer Capacitors. J. Chem. Phys. 2014, 141 (18), 184102.

(36) Yamakata, A.; Osawa, M. Destruction of the Water Layer on a Hydrophobic Surface Induced by the Forced Approach of Hydrophilic and Hydrophobic Cations. J. Phys. Chem. Lett. 2010, 1 (9), 1487-1491.

(37) Huang, B.; Muy, S.; Feng, S.; Katayama, Y.; Lu, Y.-C.; Chen, G.; Shao-Horn, Y. Non-Covalent Interactions in Electrochemical Reactions and Implications in Clean Energy Applications. Phys. Chem. Chem. Phys. 2018, 20 (23), 15680-15686.

(38) Bard, A. J.; Faulkner, L. R. Electrochemical Methods: Fundamentals and Applications, 2nd ed.; John Wiley \& Sons, Inc.: New York, 2000.

(39) Zeng, Y.; Smith, R. B.; Bai, P.; Bazant, M. Z. Simple Formula for Marcus-Hush-Chidsey Kinetics. J. Electroanal. Chem. 2014, 735, $77-83$.

(40) Bai, P.; Bazant, M. Z. Charge Transfer Kinetics at the SolidSolid Interface in Porous Electrodes. Nat. Commun. 2014, 5, 3585.

(41) Horvath, S.; Fernandez, L. E.; Soudackov, A. V.; HammesSchiffer, S. Insights into Proton-Coupled Electron Transfer Mechanisms of Electrocatalytic $\mathrm{H}_{2}$ Oxidation and Production. Proc. Natl. Acad. Sci. U. S. A. 2012, 109 (39), 15663.

(42) Costentin, C.; Evans, D. H.; Robert, M.; Savéant, J.-M.; Singh, P. S. Electrochemical Approach to Concerted Proton and Electron Transfers. Reduction of the Water-Superoxide Ion Complex. J. Am. Chem. Soc. 2005, 127 (36), 12490-12491.
(43) Boyle, D. T.; Kong, X.; Pei, A.; Rudnicki, P. E.; Shi, F.; Huang, W.; Bao, Z.; Qin, J.; Cui, Y. Transient Voltammetry with Ultramicroelectrodes Reveals the Electron Transfer Kinetics of Lithium Metal Anodes. ACS Energy Lett. 2020, 5 (3), 701-709.

(44) Fraggedakis, D.; McEldrew, M.; Smith, R. B.; Krishnan, Y.; Zhang, Y.; Bai, P.; Chueh, W. C.; Shao-Horn, Y.; Bazant, M. Z. Theory of Coupled Ion-Electron Transfer Kinetics. Electrochim. Acta 2021, 367, 137432.

(45) Santos, E.; Lundin, A.; Pötting, K.; Quaino, P.; Schmickler, W. Model for the Electrocatalysis of Hydrogen Evolution. Phys. Rev. B: Condens. Matter Mater. Phys. 2009, 79 (23), 235436.

(46) Greeley, J.; Jaramillo, T. F.; Bonde, J.; Chorkendorff, I.; Nørskov, J. K. Computational High-Throughput Screening of Electrocatalytic Materials for Hydrogen Evolution. Nat. Mater. 2006, 5 (11), 909-913.

(47) Lam, Y.-C.; Soudackov, A. V.; Hammes-Schiffer, S. Theory of Electrochemical Proton-Coupled Electron Transfer in Diabatic Vibronic Representation: Application to Proton Discharge on Metal Electrodes in Alkaline Solution. J. Phys. Chem. C 2020, 124 (50), 27309-27322.

(48) Marcus, R. A. Electron Transfer Reactions in Chemistry: Theory and Experiment (Nobel Lecture). Angew. Chem., Int. Ed. Engl. 1993, 32 (8), 1111-1121.

(49) Henstridge, M. C.; Laborda, E.; Rees, N. V.; Compton, R. G. Marcus-Hush-Chidsey Theory of Electron Transfer Applied to Voltammetry: A Review. Electrochim. Acta 2012, 84, 12-20.

(50) Chidsey, C. E. D. Free Energy and Temperature Dependence of Electron Transfer at the Metal-Electrolyte Interface. Science 1991, 251 (4996), 919.

(51) Katayama, Y.; Okanishi, T.; Muroyama, H.; Matsui, T.; Eguchi, K. Enhanced Supply of Hydroxyl Species in CeO2-Modified Platinum Catalyst Studied by in Situ ATR-FTIR Spectroscopy. ACS Catal. 2016, 6 (3), 2026-2034.

(52) Katayama, Y.; Giordano, L.; Rao, R. R.; Hwang, J.; Muroyama, H.; Matsui, T.; Eguchi, K.; Shao-Horn, Y. Surface (Electro)Chemistry of $\mathrm{CO} 2$ on Pt Surface: An in Situ Surface-Enhanced Infrared Absorption Spectroscopy Study. J. Phys. Chem. C 2018, 122 (23), 12341-12349.

(53) Marcus, Y. Effect of Ions on the Structure of Water: Structure Making and Breaking. Chem. Rev. 2009, 109 (3), 1346-1370.

(54) Chen, Q.-S.; Solla-Gullón, J.; Sun, S.-G.; Feliu, J. M. The Potential of Zero Total Charge of Pt Nanoparticles and Polycrystalline Electrodes with Different Surface Structure: The Role of Anion Adsorption in Fundamental Electrocatalysis. Electrochim. Acta 2010, 55 (27), 7982-7994.

(55) Suo, L.; Borodin, O.; Gao, T.; Olguin, M.; Ho, J.; Fan, X.; Luo, C.; Wang, C.; Xu, K. Water-in-Salt" Electrolyte Enables High-Voltage Aqueous Lithium-Ion Chemistries. Science 2015, 350 (6263), 938.

(56) Strmcnik, D.; van der Vliet, D. F.; Chang, K.-C.; Komanicky, V.; Kodama, K.; You, H.; Stamenkovic, V. R.; Marković, N. M. Effects of $\mathrm{Li}+, \mathrm{K}+$, and $\mathrm{Ba} 2+$ Cations on the ORR at Model and High Surface Area Pt and Au Surfaces in Alkaline Solutions. J. Phys. Chem. Lett. 2011, 2 (21), 2733-2736.

(57) Janik, M. J.; McCrum, I. T.; Koper, M. T. M. On the Presence of Surface Bound Hydroxyl Species on Polycrystalline Pt Electrodes in the "Hydrogen Potential Region" (0-0.4V-RHE). J. Catal. 2018, 367, 332-337.

(58) Marcus, Y. ViscosityB-Coefficients, Structural Entropies and Heat Capacities, and the Effects of Ions on the Structure of Water. J. Solution Chem. 1994, 23 (7), 831-848.

(59) Bockris, J. O.; Mauser, H. THE KINETICS OF THE EVOLUTION AND DISSOLUTION OF HYDROGEN AT ELECTRODES. Can. J. Chem. 1959, 37 (2), 475-488.

(60) Soper, A. K. The Radial Distribution Functions of Water and Ice from 220 to $673 \mathrm{~K}$ and at Pressures up to $400 \mathrm{MPa}$. Chem. Phys. 2000, 258 (2), 121-137.

(61) Liu, Y.-P.; Newton, M. D. Reorganization Energy for Electron Transfer at Film-Modified Electrode Surfaces: A Dielectric Continuum Model. J. Phys. Chem. 1994, 98 (29), 7162-7169. 
(62) Fumagalli, L.; Esfandiar, A.; Fabregas, R.; Hu, S.; Ares, P.; Janardanan, A.; Yang, Q.; Radha, B.; Taniguchi, T.; Watanabe, K.; Gomila, G.; Novoselov, K. S.; Geim, A. K. Anomalously Low Dielectric Constant of Confined Water. Science 2018, 360 (6395), 1339.

(63) Haggis, G. H.; Hasted, J. B.; Buchanan, T. J. The Dielectric Properties of Water in Solutions. J. Chem. Phys. 1952, 20 (9), 14521465.

(64) Nörtemann, K.; Hilland, J.; Kaatze, U. Dielectric Properties of Aqueous $\mathrm{NaCl}$ Solutions at Microwave Frequencies. J. Phys. Chem. A 1997, 101 (37), 6864-6869.

(65) Varghese, S.; Kannam, S. K.; Hansen, J. S.; Sathian, S. P. Effect of Hydrogen Bonds on the Dielectric Properties of Interfacial Water. Langmuir 2019, 35 (24), 8159-8166.

(66) Senapati, S.; Chandra, A. Dielectric Constant of Water Confined in a Nanocavity. J. Phys. Chem. B 2001, 105 (22), 51065109.

(67) Dinpajooh, M.; Matyushov, D. V. Dielectric Constant of Water in the Interface. J. Chem. Phys. 2016, 145 (1), 014504.

(68) Garlyyev, B.; Xue, S.; Watzele, S.; Scieszka, D.; Bandarenka, A. S. Influence of the Nature of the Alkali Metal Cations on the Electrical Double-Layer Capacitance of Model $\mathrm{Pt}(111)$ and $\mathrm{Au}(111)$ Electrodes. J. Phys. Chem. Lett. 2018, 9 (8), 1927-1930.

(69) Xue, S.; Garlyyev, B.; Auer, A.; Kunze-Liebhäuser, J.; Bandarenka, A. S. How the Nature of the Alkali Metal Cations Influences the Double-Layer Capacitance of $\mathrm{Cu}, \mathrm{Au}$, and $\mathrm{Pt}$ SingleCrystal Electrodes. J. Phys. Chem. C 2020, 124 (23), 12442-12447.

(70) Hupp, J. T.; Weaver, M. J. Solvent, Ligand, and Ionic Charge Effects on Reaction Entropies for Simple Transition-Metal Redox Couples. Inorg. Chem. 1984, 23 (22), 3639-3644.

(71) Owen, B. B.; Miller, R. C.; Milner, C. E.; Cogan, H. L. The Dielectric Constant Of Water As A Function Of Temperature And Pressure $^{1,2}$. J. Phys. Chem. 1961, 65 (11), 2065-2070.

(72) King, E. L. Ion Association. Science 1964, 143 (3601), 37.

(73) Harned, H. S.; Swindells, F. E. The Activity Coefficient Of Lithium Hydroxide In Water And In Aqueous Lithium Chloride Solutions, And The Dissociation Of Water In Lithium Chloride Solutions. J. Am. Chem. Soc. 1926, 48 (1), 126-135.

(74) Ataka, K.; Yotsuyanagi, T.; Osawa, M. Potential-Dependent Reorientation of Water Molecules at an Electrode/Electrolyte Interface Studied by Surface-Enhanced Infrared Absorption Spectroscopy. J. Phys. Chem. 1996, 100 (25), 10664-10672.

(75) Yan, Y.-G.; Li, Q.-X.; Huo, S.-J.; Ma, M.; Cai, W.-B.; Osawa, M. Ubiquitous Strategy for Probing ATR Surface-Enhanced Infrared Absorption at Platinum Group Metal-Electrolyte Interfaces. J. Phys. Chem. B 2005, 109 (16), 7900-7906.

(76) McCrum, I. T.; Chen, X.; Schwarz, K. A.; Janik, M. J.; Koper, M. T. M. Effect of Step Density and Orientation on the Apparent PH Dependence of Hydrogen and Hydroxide Adsorption on Stepped Platinum Surfaces. J. Phys. Chem. C 2018, 122 (29), 16756-16764.

(77) Rebollar, L.; Intikhab, S.; Oliveira, N. J.; Yan, Y.; Xu, B.; McCrum, I. T.; Snyder, J. D.; Tang, M. H. Beyond Adsorption" Descriptors in Hydrogen Electrocatalysis. ACS Catal. 2020, 10 (24), 14747-14762.

(78) Strmcnik, D.; Uchimura, M.; Wang, C.; Subbaraman, R.; Danilovic, N.; van der Vliet, D.; Paulikas, A. P.; Stamenkovic, V. R.; Markovic, N. M. Improving the Hydrogen Oxidation Reaction Rate by Promotion of Hydroxyl Adsorption. Nat. Chem. 2013, 5 (4), 300306.

(79) Cheng, T.; Wang, L.; Merinov, B. V.; Goddard, W. A. Explanation of Dramatic PH-Dependence of Hydrogen Binding on Noble Metal Electrode: Greatly Weakened Water Adsorption at High PH. J. Am. Chem. Soc. 2018, 140 (25), 7787-7790. 